\title{
Near Earth Asteroid Human Mission Possibilities Using Nuclear Thermal Rocket (NTR) Propulsion
}

\author{
Stanley K. Borowski ${ }^{1}$, David R. McCurdy ${ }^{2}$ and Thomas W. Packard ${ }^{2}$ \\ NASA Glenn Research Center, Cleveland, $\mathrm{OH}, 44135$
}

The NTR is a proven technology that generates high thrust and has a specific impulse ( $I_{\text {sp }} \sim 900$ s) twice that of today's best chemical rockets. During the Rover and NERVA (Nuclear Engine for Rocket Vehicle Applications) programs, twenty rocket reactors were designed, built and ground tested. These tests demonstrated: (1) a wide range of thrust; (2) high temperature carbide-based nuclear fuel; (3) sustained engine operation; (4) accumulated lifetime; and (5) restart capability - all the requirements needed for a human mission to Mars. Ceramic metal fuel was also evaluated as a backup option. In NASA's recent Mars Design reference Architecture (DRA) 5.0 study, the NTR was selected as the preferred propulsion option because of its proven technology, higher performance, lower launch mass, versatile vehicle design, simple assembly, and growth potential. In contrast to other advanced propulsion options, NTP requires no large technology scale-ups. In fact, the smallest engine tested during the Rover program - the 25 klb $_{\mathrm{f}}$ "Pewee" engine is sufficient for a human Mars mission when used in a clustered engine configuration. The "Copernicus" crewed NTR Mars transfer vehicle design developed for DRA 5.0 has significant capability that can enable reusable "1-year" round trip human missions to candidate near Earth asteroids (NEAs) like $1991 \mathrm{JW}$ in 2027, or 2000 SG344 and Apophis in 2028. A robotic precursor mission to 2000 SG344 in late 2023 could provide an attractive Flight Technology Demonstration of a small NTR engine that is scalable to the $25 \mathrm{klb}_{\mathrm{r}}$-class engine used for human missions 5 years later. In addition to the detailed scientific data gathered from on-site inspection, human NEA missions would also provide a valuable "check out" function for key elements of the NTR transfer vehicle (its propulsion module, TransHab and life support systems, etc.) in a "deep space" environment prior to undertaking the longer duration Mars orbital and landing missions that would follow. The initial mass in low Earth orbit required for a mission to Apophis is $\sim 323$ t consisting of the NTR propulsion module ( $\sim 138$ t), the integrated saddle truss and $\mathrm{LH}_{2}$ drop tank assembly $(\sim 123 \mathrm{t})$, and the 6-crew payload element ( $\sim 62$ t). The later includes a multi-mission Space Excursion Vehicle (MMSEV) used for close-up examination and sample gathering. The total burn time and required restarts on the three $25 \mathrm{klb}_{\mathrm{f}}$ "Pewee-class" engines operating at $I_{\mathrm{sp}} \sim 906 \mathrm{~s}$, are $\sim 76.2$ minutes and 4, respectively, well below the 2 hours and 27 restarts demonstrated on the NERVA eXperimental Engine, the NRX-XE. The paper examines the benefits, requirements and characteristics of using NTP for the above NEA missions. The impacts on vehicle design of HLV payload volume and lift capability, crew size, and reusability are also quantified.

\section{Nomenclature}

$\begin{array}{ll}I M L E O & =\text { initial mass in low Earth orbit } \\ K & =\text { temperature (degrees Kelvin) } \\ k l b_{f} & =\text { thrust }(1000 \text { 's of pounds force) } \\ L E O & =\text { Low Earth Orbit }(=407 \mathrm{~km} \text { circular) } \\ N T P & =\text { Nuclear Thermal Propulsion } \\ H L V & =\text { Heavy Lift Vehicle } \\ t & =\text { metric ton }(1 \mathrm{t}=1000 \mathrm{~kg}) \\ \Delta V & =\text { velocity change increment }(\mathrm{km} / \mathrm{s})\end{array}$

${ }^{1}$ DSS Branch Chief \& Lead Engineer, NTP Systems, 21000 Brookpark Road, MS: 86-4, AIAA Associate Fellow.

${ }^{2}$ Vantage Partners, LLC at Glenn Research Center, 3000 Aerospace Parkway, Brook Park, OH 44142 
AIAA-2012-4209

\section{Introduction}

$\mathrm{T}$ he Global Exploration Roadmap (GER), developed by the International Space Exploration Coordination Group (ISECG), reflects the initial efforts of NASA and 13 other space agencies to define feasible and sustainable pathways for future human space exploration that includes the Moon, near-Earth asteroids, and eventually Mars, the long-term goal of the GER [1]. The initial GER identified two possible pathways for future human missions after International Space Station (ISS) utilization. These pathways are referred to as the "Moon Next" and "Asteroid Next" scenarios. Both approaches utilize a stepwise development and demonstration of capabilities that are required for the eventual human exploration of Mars.

The "Moon Next" pathway has a strong appeal to many because unlike the United States that landed 12 men there during the Apollo program, other countries have not yet achieved this goal. At the recent 2012 Global Space Exploration Conference in Washington, DC (May 22 - 24), Vladimir A. Popovkin, head of the Russia Space Agency (Roscosmos) seemed to endorse the "Moon Next" scenario, and it is generally believed that China's National Space Administration (CNSA) has a strong interest in the Moon as well. Located just 3 days from Earth is an entire world awaiting exploration, future settlement and potential commercialization. The Moon is an ideal location to test and demonstrate key technologies and systems (e.g., surface habitation, long-range pressurized rovers, surface power and resource extraction systems) that will allow people to explore, work and learn how to live self-sufficiently on another planetary surface. Crewed NEA missions would follow that demonstrate additional inspace capabilities (e.g., advanced propulsion) needed to reach Mars. Efficient propulsion and an affordable in-space transportation system with reuse capability will also be required if initial lunar outposts are to evolve into eventual settlements capable of supporting commercial activities.

The "Asteroid Next" pathway has as its focus the development and demonstration of key in-space exploration technologies and capabilities (e.g., reliable life support systems, long duration habitation and cryogenic fluids management, and advanced propulsion) necessary for traveling through and living in deep space. In addition to the scientific knowledge gained by an "up close and personal" examination of these primordial objects, NEA missions can also provide a proving ground for validating the spacecraft systems that will be needed for sending astronauts to Mars orbit. In the GER, the ISECG shows the first crewed mission to a NEA beginning in 2028.

Deep space asteroid missions as precursors to a human Mars mission is also consistent with the United States' National Space Policy [2] that states NASA shall: By 2025, begin crewed missions beyond the Moon, including sending humans to an asteroid. By the mid-2030s, send humans to orbit Mars and return them safely to Earth. Over the last several years, NASA's Human Architecture Team has pursued a strategy, referred to as a Capability Driven Framework (CDF), which assumes the utilization of evolving capabilities to pursue more demanding missions. With $\mathrm{CDF}$, nearer-term technologies (chemical and solar electric propulsion) would be developed and demonstrated on less demanding missions (Earth-Moon libration points and NEAs) first, before developing the technologies and systems needed for Mars. Such an approach could be short-sighted and jeopardize NASA's ability to orbit Mars by 2035 by diverting resources away from proven technologies like NTP towards less capable systems that are large and operationally complex to use. Furthermore, a short ( $18-20$ month) round trip / short ( 60 day) orbital stay mission to Mars is best performed in the 2033-2035 timeframe when the mission $\Delta \mathrm{V}$ budgets are near their minimum values over the 15 -year synodic cycle. After that, the $\Delta \mathrm{V}$ budgets for successive short round trip missions increase significantly with the next minimum occurring in 2045 .

In NASA's recent Mars DRA 5.0 study [3], both short and long surface stay landing missions were considered. The "fast conjunction" long stay option was selected for the design reference because it provided adequate time at Mars ( $\sim 540$ days) for the crew to explore the planet's rich geological diversity while also reducing the crew "1-way" transit times to and from Mars to $\sim 6$ months, or $\sim 1$ year in deep space. Long surface stay missions also have lower energy requirements than the short round trip time, short surface stay "opposition-class" missions, and therefore require less propellant and less mass delivered to LEO.

The NTR was the propulsion system of choice in DRA 5.0 because of its high thrust $(10$ 's of klb $)$ and high specific impulse $\left(\mathrm{I}_{\mathrm{sp}} \sim 900-950 \mathrm{~s}\right)$, its increased tolerance to payload mass growth and architecture changes, and its lower IMLEO which is important for reducing the HLV launch count, overall mission cost and risk. With a $100 \%$ higher $I_{\text {sp }}$ than today's best chemical rockets, the use of NTP reduced the required launch mass by over $400 t-$ the equivalent mass of the ISS. More importantly, the NTR is a proven technology and the only advanced propulsion option to be successfully ground tested at the performance levels required for a human mission to Mars. No large technology or performance scale-ups are needed as with other propulsion options. In fact, the smallest and highest performing engine tested during the Rover / NERVA programs [4] - the $25 \mathrm{klb}_{\mathrm{f}}$ "Pewee" engine is sufficient for a human mission to Mars when used in a clustered engine arrangement. 
DRA 5.0 featured a "split mission" approach using separate cargo and crewed Mars transfer vehicles (MTVs). Both vehicle types utilized a common "core" propulsion stage each with three $25 \mathrm{klb}_{\mathrm{f}}$ "composite fuel" Pewee-class engines. Two cargo vehicles were used to pre-deploy surface and orbital assets to Mars ahead of the crew who arrived during the next mission opportunity ( 26 months later). The crewed MTV called "Copernicus" [5, 6] is a zero-gravity $\left(0-\mathrm{g}_{\mathrm{E}}\right)$ vehicle design consisting of three basic components: (1) the crewed payload element; (2) the NTR propulsion stage; and (3) an integrated "saddle truss" and liquid hydrogen $\left(\mathrm{LH}_{2}\right)$ propellant drop tank assembly that connects the payload and propulsion elements. The spacecraft was sized to allow it to perform all of the fastconjunction missions over the 15-year synodic cycle. It therefore has significant capability that can be utilized for near Earth asteroid (NEA) missions currently under study by NASA and the ISECG. The Copernicus spacecraft, outfitted as an Asteroid Survey Vehicle (ASV) is called "Searcher" and is illustrated in Fig. 1.

This paper presents analysis supporting an alternative human exploration strategy that utilizes a "Technology Driven Framework" focused on developing and demonstrating the technologies and systems found in Copernicus' two key elements, its propulsion stage and integrated saddle truss / drop tank assembly, then validating them on candidate "1-year" round trip NEA missions in the late 2020's in preparation for an orbital Mars mission in 2033. By focusing the resources of NASA and other space agencies on developing several key technologies and systems (the NTR, reverse turbo-Brayton refrigeration for zero-boiloff $\mathrm{LH}_{2}$ storage, and large composite structures) and exploiting the technology synergies that exist between Copernicus, the HLV (e.g., large aluminum / lithium (A1/Li) $\mathrm{LH}_{2}$ tanks) and existing flight-tested chemical rocket hardware (e.g., $\mathrm{LH}_{2}$ turbopumps, regenerative- and radiationcooled nozzles and skirt extensions), substantial savings in development time and cost are expected.

This paper examines the benefits of using NTP for human NEA missions and covers a number of topic areas. Considerations in the selection of candidate NEA targets are discussed first. Then the operational principles and performance characteristics of the baseline $25 \mathrm{klb}_{\mathrm{f}}$ NTR engine used in this analysis are presented along with a summary of the Rover/NERVA programs' technical accomplishments. Mission and transportation system ground rules and assumptions are provided next followed by an overview of the Concepts of Operations (ConOps) for both reusable and expendable NEA mission options analyzed in this paper. Results are then presented for three candidate NEA missions in the late 2020's that include the key features and operational characteristics for a variety of crewed ASV configurations / options. The impacts on crewed vehicle design of the heavy launch vehicle's payload volume and lift capability, crew size and reusability are also examined. Future system-level Technology Demonstrations of NTP over the next 10 years could include ground and flight testing of a small scalable NTR. A robotic NEA precursor mission in late 2023 could provide an attractive Flight Technology Demonstration of a small NTR engine while also providing valuable scientific data needed for planning a human mission 5 years later. The paper ends with a summary of our findings and some concluding remarks.

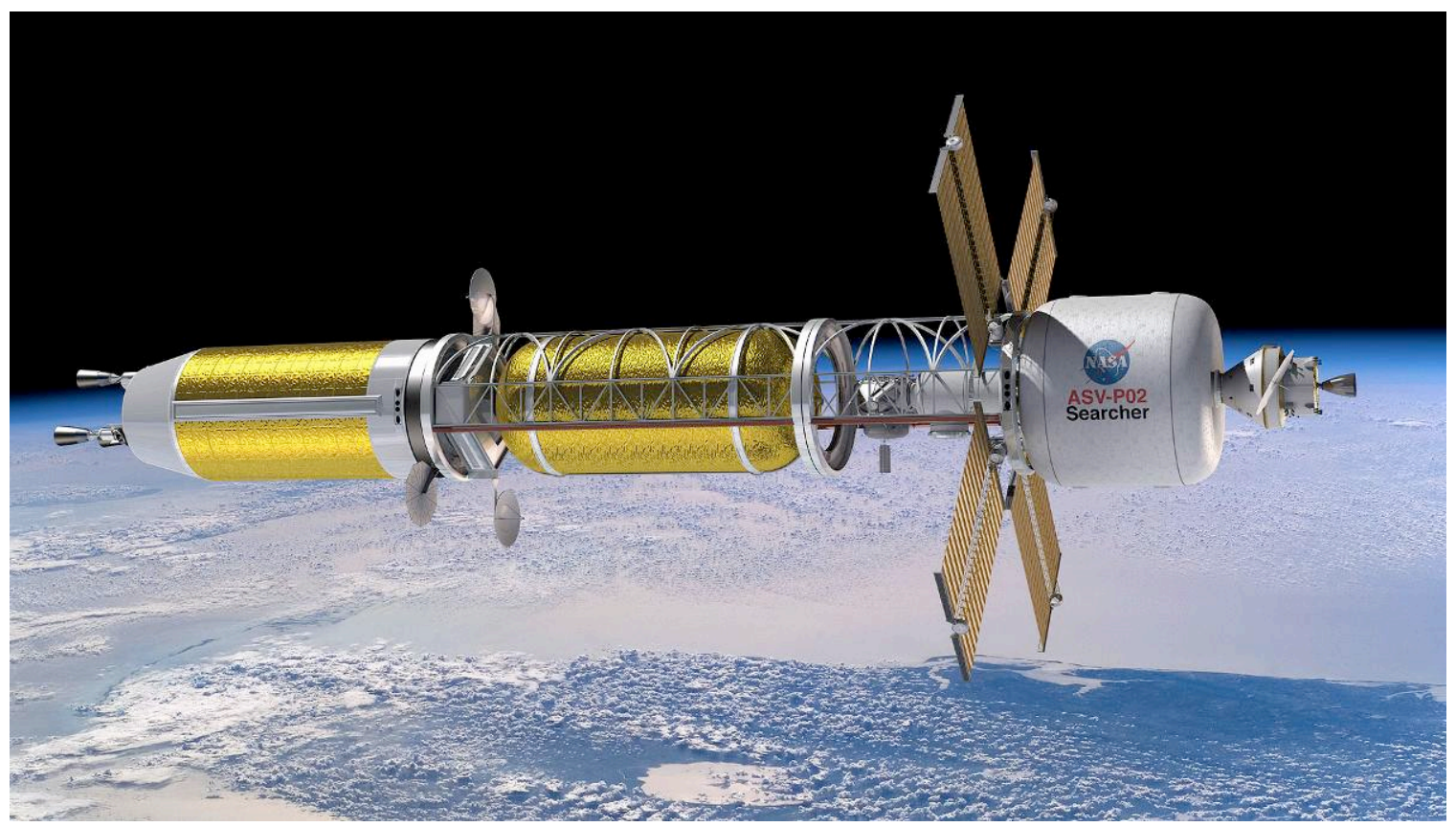

Figure 1. Crewed NTR Asteroid Survey Vehicle "Searcher" in LEO Prior to Departure 


\section{Considerations Involved in Planning Human NEA Missions}

There are many considerations that must be taken into account in planning a human NEA mission. A comprehensive review of these considerations is found in a paper by Drake [7]. While NEAs orbit relatively close to Earth (orbit perihelion typically $<1.3$ Astronomical Units), missions to them can be considered "deep space missions" in the sense that they break from Earth's orbit and fly heliocentric trajectories that are bound by the Sun. Also, because the synodic periods for many NEA targets are long ( $\sim 5-30$ years $)$, asset pre-deployment is difficult so crewed missions must carry everything needed for the round trip - referred to as "all-up" mission approach.

A variety of criteria must be considered in evaluating the overall accessibility of candidate NEAs for human exploration [7]. Some key evaluation criteria include the: (1) Mission date; (2) Asteroid size and characteristics; (3) Synodic period; (4) Total launch / mission mass; (5) Mission duration; and (6) Departure window characteristics. As mentioned above, the current ISECG GER shows the first crewed mission to a NEA beginning in 2028. This date is consistent with "preliminary" development plans that envision an Initial Operational Capability (IOC) for a crewed NTP transportation system in this same timeframe. A decision to fly an earlier NEA mission could eliminate the NTP option and involve investing in and developing less capable propulsion options that would cost more and require additional launch mass not just for the NEA mission but for the Mars orbital mission to follow.

Information on NEA characteristics and size will be important in planning a safe and affordable human mission. There is considerable uncertainty and lack of knowledge about the characteristics of many candidate NEAs currently under study (Fig. 2). One of the most important criteria determining the suitability of a NEA for human exploration is its size. There is a strong correlation between asteroid size and spin rate [7,8]. Small asteroids, on the order of 50 $-100 \mathrm{~m}$, are likely to be fast rotating and have a monolithic composition with less surface regolith. Large asteroids $100 \mathrm{~m}$ or larger, tend to rotate more slowly and have a high probability of being rubble piles of rock like asteroid Itokawa shown in Fig. 3. To allow astronauts direct contact and sampling of the NEA surface, a slow spin rate and an ability to anchor to the surface are highly desirable. Large NEAs are also likely to have a greater diversity of surface terrain and material composition desired by the scientific community.

While ground-based (optical and radar) and space-based observational surveys can help provide some of the data needed for target characterization (spin rate, spectral class, albedo/size, etc.), dedicated robotic precursor missions sent to orbit and study multiple targets years in advance of a human mission may be the best approach to achieving an acceptable programmatic and crew risk by validating an intended NEA selection or selections.

According to Drake [7], of the 7655 known NEAs catalogued in the Small Bodies Database managed by JPL, there are $~ 75-159$ "accessible" targets that fit within the timeframe of interest $(2025-2035)$ and that meet or exceed the lower size limit of $\sim 30$ meters. Because the number of discovered NEAs is thought to be only a few percent of the entire NEA population, it is expected that the number of available targets will continue to grow.

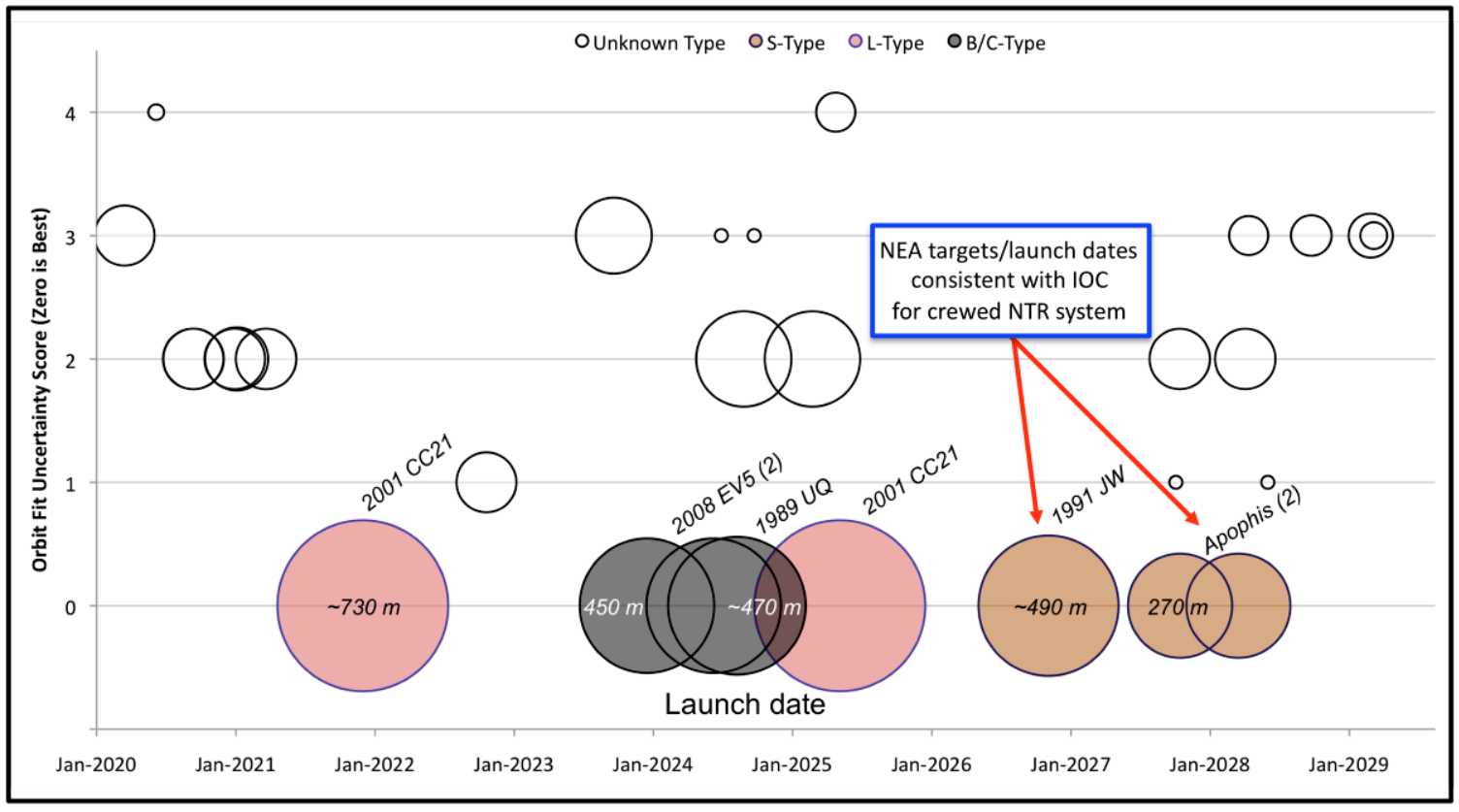

Figure 2. Orbit Uncertainty, Asteroid Size, and Spectral Type vs. Launch date 


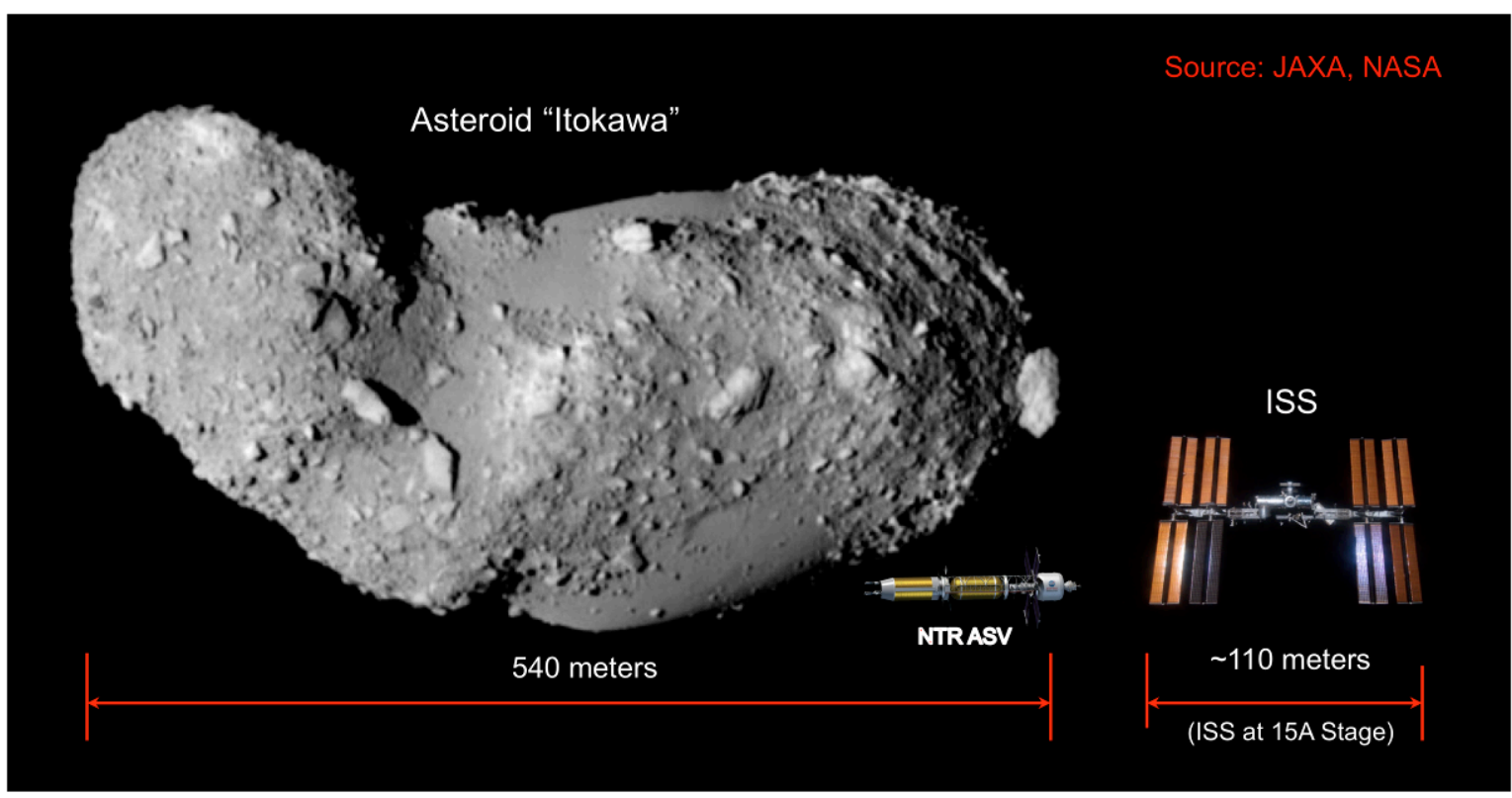

Fig. 3. Relative Size of Asteroid Itokwa, ISS and a Reusable NTR Asteroid Survey Vehicle

In this paper we examine the benefits of using NTP for human missions to both small, low energy and large, higher energy NEA targets. Table 1 shows a small sampling of NEA targets for both mission classes. The small NEA selected is $2000 \mathrm{SG} 344$. It has a 2028 mission launch date consistent with NTP IOC, a modest $\Delta \mathrm{V}$ requirement of $\sim 3.79 \mathrm{~km} / \mathrm{s}$ and a round trip time of $\sim 327$ days that includes a 7 day NEA stay time. Increasing the $\Delta \mathrm{V}$ decreases the round trip time and increases stay time. However, because no direct observations of size are available for 2000 SG344, its size and rotation rate must be estimated from visual brightness. The opportunity for a robotic precursor mission in October 2023 would be able to provide other key data and could also provide an attractive Flight Technology Demonstration mission for a small NTR engine that would be scalable to the full size $25 \mathrm{klb}_{\mathrm{f}}$ engine that would then be used on the human mission 5 years later.

Two large, higher energy NEA missions are also examined (see Fig. 2) - one to Apophis in 2028 (see Table 1) and the other to $1991 \mathrm{JW}$ in 2027 (details provided in Fig. 15). Apophis is of particular interest because on Friday, April 13, 2029, it will pass Earth's surface at an altitude of $\sim 18,300$ miles - within the orbits of geosynchronous communications satellites [9]. It will return for another close Earth approach in 2036.

Table 1. Sampling of Low and High Energy NEA Targets for Future Human Exploration

\begin{tabular}{|c|c|c|c|c|c|c|c|c|c|c|c|}
\hline \multirow{2}{*}{$\begin{array}{c}\text { NEA } \\
\text { Designation } \\
\text { and } \\
\text { Approx. Size }\end{array}$} & \multirow{2}{*}{$\begin{array}{l}\text { Mission } \\
\text { Type }\end{array}$} & \multicolumn{3}{|c|}{$\begin{array}{c}\text { Earth Departure } \\
\text { (LEO Parking Orbit Alt: } 400 \text { km) }\end{array}$} & \multicolumn{2}{|c|}{ Outbound } & \multicolumn{2}{|c|}{ at NEA } & \multirow{2}{*}{$\begin{array}{c}\text { Inbound } \\
\begin{array}{c}\text { TOF } \\
\text { (days) }\end{array}\end{array}$} & \multicolumn{2}{|c|}{ Mission Totals } \\
\hline & & Date & $\begin{array}{c}\mathrm{C} 3 \\
\left(\mathrm{~km}^{2} / \mathrm{s}^{2}\right)\end{array}$ & $\begin{array}{c}\Delta \mathrm{V} \\
(\mathrm{km} / \mathrm{s})\end{array}$ & $\begin{array}{c}\text { TOF } \\
\text { (days) }\end{array}$ & $\begin{array}{c}\text { Arrival } \Delta V \\
(\mathrm{~km} / \mathrm{s})\end{array}$ & $\begin{array}{l}\text { Stay Time } \\
\text { (days) }\end{array}$ & $\begin{array}{l}\text { Departure } \\
\Delta \mathrm{V}(\mathrm{km} / \mathrm{s})\end{array}$ & & $\begin{array}{l}\text { Total } \Delta \mathrm{V} \\
(\mathrm{km} / \mathrm{s})\end{array}$ & $\begin{array}{l}\text { RT Time } \\
\text { (days) }\end{array}$ \\
\hline \multicolumn{12}{|c|}{ Low Energy Missions } \\
\hline 2009 HC & Robotic Precursor & $12 / 12 / 22$ & 5.323 & 3.419 & 363 & 1.924 & & & & & \\
\hline$(\sim 30-66 \mathrm{~m})$ & Human Mission & $10 / 18 / 25$ & 11.131 & 3.678 & 81 & 0.338 & 7 & 0.540 & 273 & 4.566 & 361 \\
\hline \multirow{5}{*}{$\begin{array}{l}2000 \text { SG344 } \\
(\sim 29-65 \mathrm{~m})\end{array}$} & Robotic Precursor & $10 / 6 / 23$ & 1.809 & 3.260 & 383 & 1.655 & & & & & \\
\hline & Human Mission & $4 / 27 / 28$ & 1.680 & 3.254 & 104 & 0.144 & 7 & 0.392 & 216 & 3.790 & 327 \\
\hline & Human Mission & $4 / 28 / 28$ & 1.680 & 3.254 & 96 & 0.142 & 14 & 0.399 & 214 & 3.794 & 324 \\
\hline & Human Mission & $4 / 28 / 28$ & 1.640 & 3.252 & 92 & 0.154 & 21 & 0.408 & 208 & 3.814 & 321 \\
\hline & Human Mission & $4 / 28 / 28$ & 1.640 & 3.252 & 88 & 0.169 & 28 & 0.417 & 203 & 3.839 & 319 \\
\hline \multicolumn{12}{|c|}{ High Energy Missions } \\
\hline 2008 EV5 & Robotic Precursor & $12 / 25 / 21$ & 21.520 & 4.127 & 381 & 2.354 & & & & & \\
\hline$(\sim 266-594 m)$ & Human Mission & $6 / 22 / 24$ & 14.143 & 3.810 & 211 & 1.203 & 30 & 2.766 & 126 & 7.779 & 367 \\
\hline \multirow{2}{*}{$\begin{array}{c}\text { Apophis } \\
(\sim 270-350 \mathrm{~m}) \\
\end{array}$} & Robotic Precursor & $10 / 17 / 21$ & 28.735 & 4.429 & 269 & 0.356 & & & & & \\
\hline & Human Mission & $5 / 8 / 28$ & 13.525 & 3.783 & 268 & 1.542 & 7 & 0.342 & 69 & 5.667 & 344 \\
\hline
\end{tabular}




\section{NTR System Description and Performance Characteristics}

The NTR uses a compact fission reactor core containing 93\% "enriched" Uranium (U)-235 fuel to generate 100's of megawatts of thermal power $\left(\mathrm{MW}_{\mathrm{t}}\right)$ required to heat the $\mathrm{LH}_{2}$ propellant to high exhaust temperatures for rocket thrust. In an "expander cycle" Rover/NERVA-type engine (Fig. 4), high pressure $\mathrm{LH}_{2}$ flowing from twin turbopump assemblies (TPAs) cool the engine's nozzle, pressure vessel, neutron reflector, and control drums, and in the process picks up heat to drive the turbines. The turbine exhaust is then routed through the core support structure, internal radiation shield, and coolant channels in the reactor core's fuel elements where it absorbs energy produced from the fission of U-235 atoms, is superheated to high exhaust temperatures $\left(T_{\mathrm{ex}} \sim 2550-3000\right.$ degrees $\mathrm{K}$ depending on fuel type and uranium loading), then expanded out a high area ratio nozzle $(\varepsilon \sim 300: 1-500: 1)$ for thrust generation.

Controlling the NTR during its various operational phases (startup, full thrust and shutdown) is accomplished by matching the TPA-supplied $\mathrm{LH}_{2}$ flow to the reactor power level. Multiple control drums, located in the reflector region surrounding the reactor core, regulate the neutron population and reactor power level over the NTR's operational lifetime. The internal neutron and gamma radiation shield, located within the engine's pressure vessel, contains its own interior coolant channels. It is placed between the reactor core and key engine components to prevent excessive radiation heating and material damage.

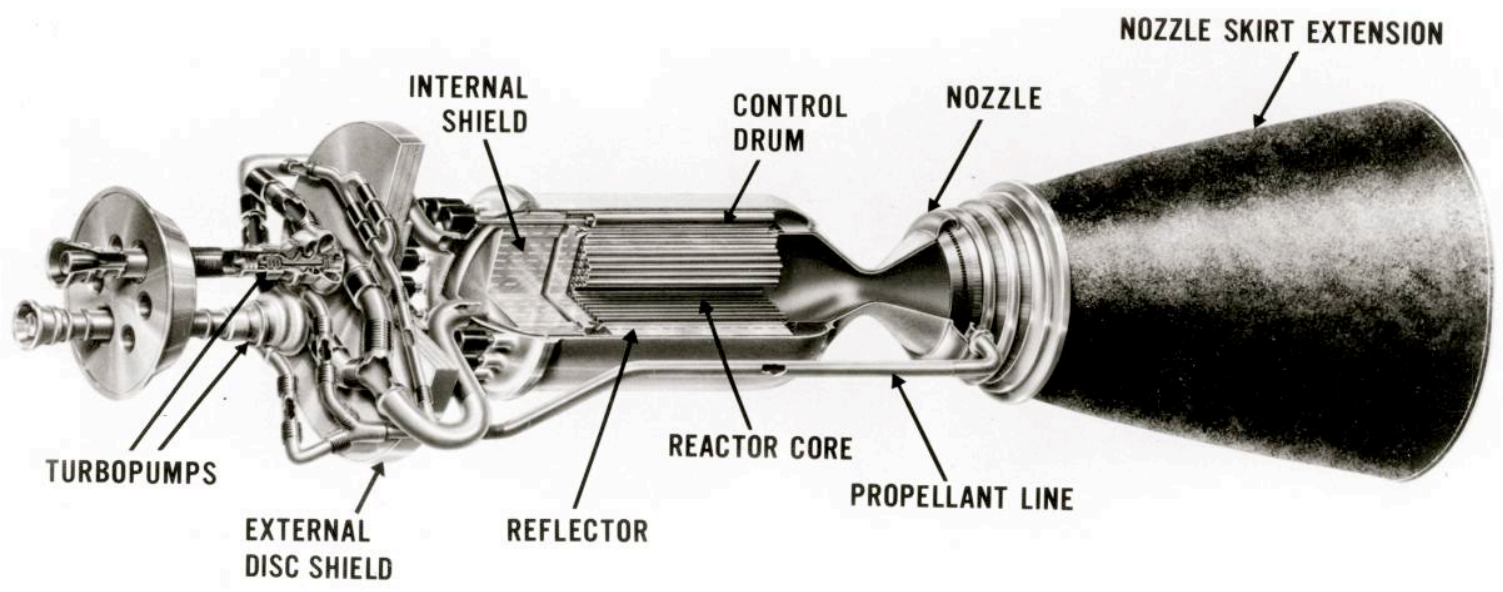

Figure 4. Schematic of "Expander Cycle" NTR Engine with Dual $\mathrm{LH}_{2}$ Turbopumps

A Rover / NERVA-derived engine uses a "graphite matrix" material fuel element (FE) containing the U-235 fuel in the form of either coated particles of uranium carbide $\left(\mathrm{UC}_{2}\right)$ or as a dispersion of uranium and zirconium carbide (UC-ZrC) within the matrix material, referred to as "composite" fuel (shown in Fig. 5). The basic FE [4] has a hexagonal cross section ( $\sim 0.75$ " across the flats), is 52" long and produces $\sim 1 \mathrm{MW}_{\mathrm{t}}$. Each FE has 19 axial coolant channels, which along with the element's exterior surfaces, are coated with $\mathrm{ZrC}$ using chemical vapor deposition (CVD) to reduce hydrogen erosion of the graphite. This basic shape was introduced in the KIWI-B4E and became the standard used in the $75 \mathrm{klb}_{\mathrm{f}}$ Phoebus-1B, $250 \mathrm{klb}_{\mathrm{f}}$ Phoebus-2A, $25 \mathrm{klb}_{\mathrm{f}}$ Pewee and the $55 \mathrm{klb}_{\mathrm{f}}$ NERVA NRX series of engines. These elements were bundled around and supported by cooled coaxial core support tie tubes. Six elements per tie tube were used in the higher power Phoebus and NRX reactor series. In the smaller Pewee engine, the ratio was reduced to three elements per tie tube. To provide sufficient neutron moderation and criticality in the smaller Pewee core, sleeves of zirconium hydride moderator material were added to the core support tie tubes (shown in Fig. 5).

The Rover program's $25 \mathrm{klb}_{\mathrm{f}}$ Pewee engine [4] was designed and built to evaluate higher temperature, longer life fuel elements with improved coatings, and in the process Pewee set several performance records. The Pewee full power test consisted of two 20-minute-long burns at the design power level of $\sim 503 \mathrm{MW}_{\mathrm{t}}$ and an average fuel element exit gas temperature of $\sim 2550 \mathrm{~K}$, the highest achieved in the Rover/NERVA nuclear rocket programs. The peak fuel temperature also reached a record level of $\sim 2750 \mathrm{~K}$. Other performance records included average and peak power densities in the reactor core of $\sim 2340 \mathrm{MW}_{\mathrm{t}} / \mathrm{m}^{3}$ and $\sim 5200 \mathrm{MW}_{\mathrm{t}} / \mathrm{m}^{3}$, respectively. A new CVD coating of $\mathrm{ZrC}$ was also introduced and used in Pewee that showed performance superior to the niobium carbide $(\mathrm{NbC})$ coating used in previous reactor tests. 
AIAA-2012-4209

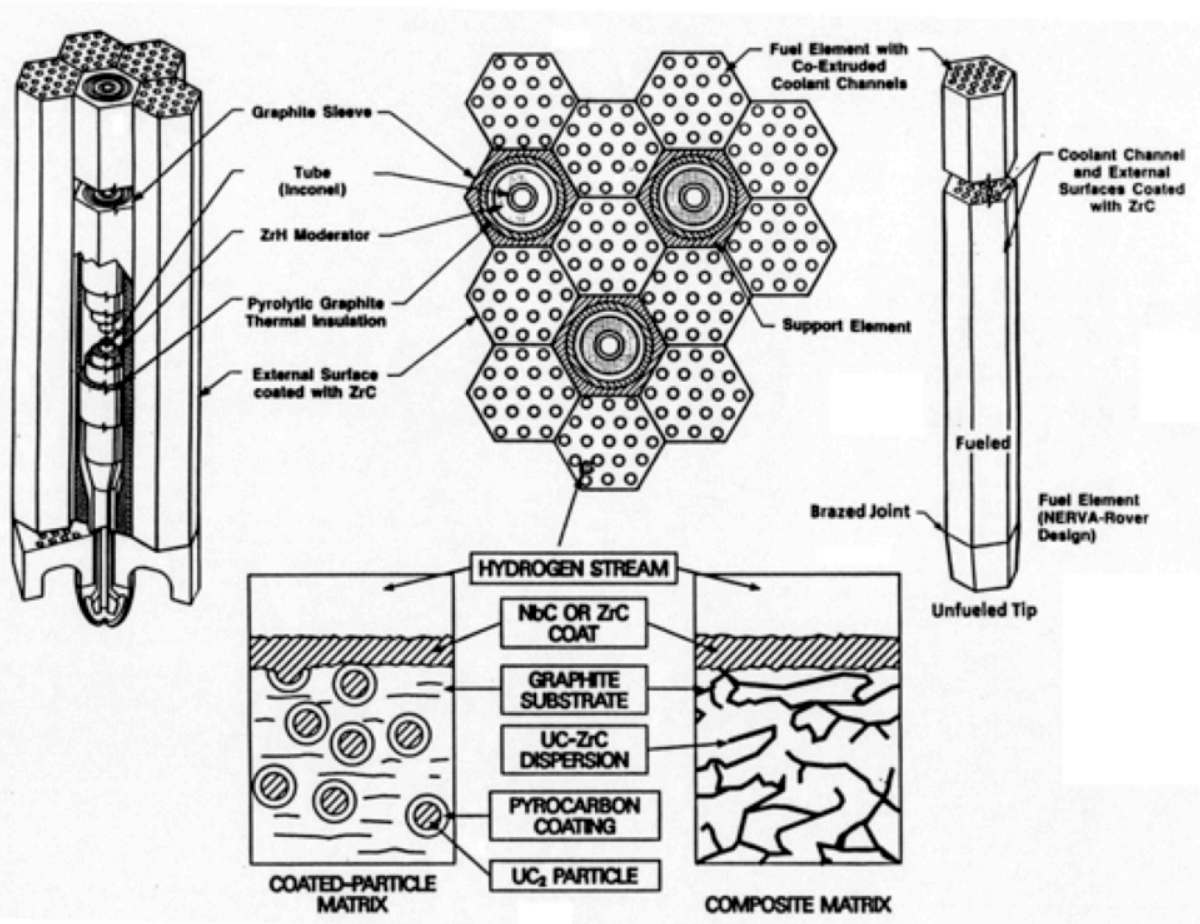

Figure 5. Coated Particle and Composite Rover / NERVA Fuel Element and Tie Tube Arrangement

In follow on tests in the "Nuclear Furnace" fuel element test reactor [4], higher temperature composite fuel elements with $\mathrm{ZrC}$ coating were evaluated. They withstood peak power densities of $\sim 4500-5000 \mathrm{MW} / \mathrm{m}^{3}$ and also demonstrated better corrosion resistance than the standard coated particle graphite matrix fuel element used in the previous Rover/NERVA reactor tests. Composite fuel's improved corrosion resistance is attributed to its higher coefficient of thermal expansion (CTE) that more closely matches that of the protective $\mathrm{ZrC}$ coating, thereby helping to reduce coating cracking. Electrical-heated composite fuel elements were also tested by Westinghouse in hot hydrogen at $2700 \mathrm{~K}$ for $\sim 600$ minutes - ten 1-hour cycles. At the end of Rover/NERVA, composite fuel performance projections [10] were estimated at $\sim 2-6$ hours at full power for hydrogen exhaust temperatures of $\sim 2500-2800 \mathrm{~K}$ and fuel loadings in the range of $\sim 0.60$ to $0.45 \mathrm{grams} / \mathrm{cm}^{3}$. In addition to these carbide-based fuels, a ceramic-metallic or "cermet" fuel consisting of uranium dioxide $\left(\mathrm{UO}_{2}\right)$ in a tungsten $(\mathrm{W})$ metal matrix was developed in the GE-710 and ANL nuclear rocket programs [11,12] as a backup to the Rover/NERVA fuel. While no integrated reactor/engine tests were conducted, a large number of fuel specimens were produced and exposed to non-nuclear hot $\mathrm{H}_{2}$ and irradiation testing with promising results. Both fuel options are under development today.

The NTR engine baselined in DRA 5.0 and in this analysis is a $25 \mathrm{klb}_{\mathrm{f}}$ "Pewee-class" expander cycle engine with the following performance parameters: $\mathrm{T}_{\mathrm{ex}} \sim 2790 \mathrm{~K}$, chamber pressure $\sim 1000$ psia, $\varepsilon \sim 300: 1$, and $\mathrm{I}_{\mathrm{sp}} \sim 906 \mathrm{~s}$. The $\mathrm{LH}_{2}$ flow rate is $\sim 12.5 \mathrm{~kg} / \mathrm{s}$ and the engine thrust-to-weight ratio is $\sim 3.50$. The overall engine length is $\sim 7.01 \mathrm{~m}$, which includes an $\sim 2.16 \mathrm{~m}$ long, retractable radiation-cooled nozzle skirt extension. The corresponding nozzle exit diameter is $\sim 1.87 \mathrm{~m}$. Recent Monte Carlo N-Particle (MCNP) transport modeling of the engine's reactor core [13], indicates that an $\mathrm{I}_{\mathrm{sp}}$ range of $\sim 894 \mathrm{~s}$ to $940 \mathrm{~s}$ is achievable by increasing the FE length from $0.89 \mathrm{~m}$ to $1.32 \mathrm{~m}$ and lowering the U-235 fuel loading in the core from $\sim 0.45$ to $0.25 \mathrm{grams} / \mathrm{cm}^{3}$ which allows the peak fuel temperature to increase while still staying safely below the melt temperature.

Lastly, the state-of-the-art for NTP can be summarized as follows: It is a proven technology! A high technology readiness level (TRL 5-6) was demonstrated during the Rover / NERVA programs (1955-1972) [4]. Twenty rocket reactors were designed, built and ground tested in integrated reactor / engine tests that demonstrated: (1) a wide range of thrust levels $\left(\sim 25,50,75\right.$ and $\left.250 \mathrm{klb}_{\mathrm{f}}\right)$; (2) high temperature carbide-based nuclear fuels that provided hydrogen exhaust temperatures up to $2550 \mathrm{~K}$ (achieved in the Pewee engine); (3) sustained engine operation (over 62 minutes for a single burn on the NRX-A6); as well as; (4) accumulated lifetime; and (5) restart capability (>2 hours during 28 startup and shutdown cycles on the NRX-XE experimental engine) - all the requirements needed for future human NEA and Mars exploration missions. 


\section{Mission and Transportation System Ground Rules and Assumptions}

Specific mission and NTR transportation system ground rules and assumptions used in this paper are summarized in Tables 2 and 3, respectively. Table 2 provides information about operational scenarios, assumed departure and return orbits at Earth, mission destinations and dates. Corresponding trip times and $\Delta \mathrm{V}$ budgets are provided in Table 1 and in Fig. 15. In addition to the large $\Delta \mathrm{V}$ requirements for the primary propulsion maneuvers [trans-NEA injection (TNI), vehicle braking and rendezvous with the target NEA and trans-Earth injection (TEI)], smaller $\Delta \mathrm{V}$ maneuvers are also needed for rendezvous and docking (R\&D) of ASV components during the LEO assembly phase, for spacecraft attitude control during in-space transit, and for NEA orbital operations.

For the crewed missions examined here, the mass of some key payload elements, like the transit habitat, varies with crew size, mission destination and duration. With increasing crew size and mission duration, additional life support, food and accommodations are needed. A short saddle truss connects the transit habitat to the rest of the spacecraft and has the same diameter as the long saddle truss that is sized by the diameter of the ASV's $\mathrm{LH}_{2}$ drop tank (see Fig. 1). The mass of both truss segments therefore increases with tank diameter.

Fixed mass payload elements include the Orion Multi-Purpose Crew Vehicle (MPCV) and an auxiliary multimission space excursion vehicle (MMSEV). The MMSEV provides a small livable volume for a crew of two for up to two weeks [7] and is attached to the TransHab module via a transfer tunnel enclosed within the short saddle truss (shown in Figure 6). The MMSEV provides $\sim 200-300 \mathrm{~m} / \mathrm{s}$ of translational $\Delta \mathrm{V}$, suitports for quick EVA capability, and remote manipulation capability for sample collection. For the NEO missions analyzed in this paper, it is assumed that the crew will collect and return $\sim 100 \mathrm{~kg}$ of samples.

\section{Table 2. Mission and Payload Ground Rules and Assumptions}

\begin{tabular}{|c|c|}
\hline $\begin{array}{l}\text { Mission Profiles / "Concepts of Operations" } \\
\text { (ConOps): }\end{array}$ & $\begin{array}{l}\text { - "All-Up" mission profile is the baseline; no asset pre-deployment } \\
\text { - "Fully Reusable" scenario; ASV and all payload elements are } \\
\text { returned to Earth orbit } \\
\text { - "Expendable" scenario; auxiliary multi-mission space excursion } \\
\text { vehicle (MMSEV) left at target NEA; ASV flies by Earth at high } \\
\text { altitude and is disposed of in heliocentric space } \\
\text { - Capsule recovery of crew at Earth at mission end }\end{array}$ \\
\hline $\begin{array}{l}\text { Missions depart from low Earth orbit (LEO) and } \\
\text { return to a 24-hr highly elliptical Earth orbit (HEEO) } \\
\text { for reusable mission scenarios }\end{array}$ & $\begin{array}{l}\text { - LEO: } 407 \mathrm{~km} \text { circular } \\
\text { - HEEO: } 500 \mathrm{~km} \times 71,136 \mathrm{~km}\end{array}$ \\
\hline $\begin{array}{l}\text { Small / Low Energy NEA Target: } \\
\text { - } 2000 \text { SG344 in } 2028\end{array}$ & $\begin{array}{l}\text { - Mission } \mathrm{C}_{3} \text {, trip time and } \Delta \mathrm{V} \text { budget details provided in Table } 1 \\
\text { - NOTE: Gravity losses added to above Ideal } \Delta \text { Vs (value of g-loss } \\
\text { depends on } \mathrm{C}_{3} \text {, vehicle } \mathrm{T} / \mathrm{W} \text {, Isp) }\end{array}$ \\
\hline $\begin{array}{l}\text { Large / High Energy NEA Targets: } \\
\text { • } 1991 \text { JW in } 2027 \\
\text { • "Apophis" (2004 MN4) in } 2028\end{array}$ & $\begin{array}{l}\text { - Mission } \mathrm{C}_{3} \text {, trip time and } \Delta \mathrm{V} \text { budget details for } 1991 \mathrm{JW} \\
\text { provided in Fig. } 15 \\
\text { - Mission } \mathrm{C}_{3} \text {, trip time and } \Delta \mathrm{V} \text { budget details for Apophis } \\
\text { provided in Table } 1 \\
\text { - NOTE: Gravity losses added to above Ideal } \Delta \mathrm{Vs} \text { (value of g-loss } \\
\text { depends on } \mathrm{C}_{3} \text {, vehicle } \mathrm{T} / \mathrm{W} \text {, Isp) }\end{array}$ \\
\hline $\begin{array}{l}\text { Additional } \Delta V \text { Requirements: Advanced Material } \\
\text { Bipropellant Rocket (AMBR) RCS thrusters used } \\
\text { to perform non-primary propulsion maneuvers }\end{array}$ & $\begin{array}{l}\text { - LEO R\&D between orbital elements: } \sim 15-50 \mathrm{~m} / \mathrm{s} \\
\text { - Coast attitude control and mid - course correction: } \\
\sim 15 \mathrm{~m} / \mathrm{s} \text { and } \sim 50 \mathrm{~m} / \mathrm{s} \text {, respectively }\end{array}$ \\
\hline $\begin{array}{l}\text { NEA Crewed Payload Mass: Varies with crew size } \\
\text { and mission duration; consumables based on a } \\
\text { crew consumption rate of } \sim 2.45 \mathrm{~kg} / \text { person/day; it is } \\
\text { assumed that a year's worth of consumables can be } \\
\text { stored in the Transit Habitat; the payload element } \\
\text { also includes a short saddle truss (SST), a transfer } \\
\text { tunnel with second docking module (TDM) plus the } \\
\text { MMSEV for NEA inspection \& sample gathering }\end{array}$ & $\begin{array}{lc}\text { - Transit Habitat: } & 22.7 \mathrm{t}-27.5 \mathrm{t} \text { (minus consumables) } \\
\text { - SST: } & 2.89 \mathrm{t}-5.08 \mathrm{t} \\
\text { - TDM: } & 1.76 \mathrm{t} \\
\text { - Crew (4-6): } & 0.4 \mathrm{t}-0.6 \mathrm{t} \\
\text { - Total Consumables: } & 3.58 \mathrm{t}-5.37 \mathrm{t}(4-6 \mathrm{crew} \text { for } 1-\mathrm{yr}) \\
\text { - MMSEV: } & 6.7 \mathrm{t} \\
\text { - CEV / SM: } & 10.0 \mathrm{t} \\
\text { - Returned NEA Samples: } & 0.1 \mathrm{t}\end{array}$ \\
\hline
\end{tabular}


Table 3 lists the key transportation system ground rules and assumptions. The NTR engine and fuel type, operating characteristics, and thrust levels examined are summarized first. A three engine cluster of $25 \mathrm{klb}_{\mathrm{f}}$ "Peweeclass" engines is baselined although lower thrust $15 \mathrm{klb}_{\mathrm{f}}$ engines have also been considered. All engines use composite fuel with a U-235 fuel loading of $0.25 \mathrm{~g} / \mathrm{cm}^{3}$. With a hydrogen exhaust temperature $\left(\mathrm{T}_{\mathrm{ex}}\right)$ of $\sim 2790 \mathrm{~K}$, and a nozzle area expansion ratio of $\sim 300: 1$, the $\mathrm{I}_{\mathrm{sp}}$ is $\sim 906 \mathrm{~s}$ with higher $\mathrm{I}_{\mathrm{sp}}$ values achievable by increasing the fuel operating temperature. The total $\mathrm{LH}_{2}$ propellant loading for a NEA mission consists of the usable propellant plus performance reserve, post-burn engine cooldown, and tank trapped residuals. For the smaller auxiliary maneuvers, a storable bipropellant RCS system is used. Each ASV configuration utilizes a "split RCS" with 16 of 32 thrusters and approximately half of the bipropellant mass located on the rear propulsion stage and the short saddle truss forward adaptor ring just behind the TransHab module.

The $\mathrm{LH}_{2}$ propellant carried by the ASV is stored in the same "state-of-the-art" $\mathrm{Al} / \mathrm{Li} \mathrm{LH}_{2}$ propellant tank that would be developed for the Space Launch System (SLS) / HLV and used for future human exploration missions. For this analysis, tank sizing assumes a 30 psi ullage pressure, $5 \mathrm{~g}_{\mathrm{E}}$ axial / $2.5 \mathrm{~g}_{\mathrm{E}}$ lateral launch loads, and a safety factor of 1.5. A 3\% ullage factor is also assumed. All tanks use a combination foam / multilayer insulation (MLI) system for passive thermal protection. A zero boil-off (ZBO) "reverse turbo-Brayton" cryocooler system is used on each NTR propulsion module $\mathrm{LH}_{2}$ tank to eliminate boiloff during LEO assembly and during travel to and from the target NEA. The propellant tank heat load is largest in LEO and sizes the ZBO cryocooler system. Solar photovoltaic arrays supply the needed primary electrical power for the ASV systems.

Table 3 also provides the assumed "dry weight contingency" (DWC) factors, along with HLV lift and shroud payload envelope requirements. A $30 \%$ DWC is used on the NTR system and advanced composite structures (e.g., stage adaptors, trusses) and 15\% on heritage systems (e.g., Al/Li tanks, RCS, etc.). The crewed ASV's propulsion stage and payload element drive the SLS / HLV lift capability and shroud size, respectively. The crewed payload (PL) element includes the "packaged" TransHab module with PVA power system, the short saddle truss, MMSEV, transfer tunnel with secondary docking module, and the Orion MPCV (see Fig. 6). The PL envelope's diameter varies from $\sim 8.6 \mathrm{~m}-11 \mathrm{~m}$ and its length can be up to $\sim 33.8 \mathrm{~m}$ (including the MPCV attached to the front end of the TransHab). The propulsion stage mass drives the SLS / HLV lift requirement which can vary from $\sim 70-140 \mathrm{t}$.

\section{Human NEA Mission Scenario Options}

Two mission scenarios - one "fully reusable" and the other "expendable" - are analyzed in this paper. The ConOps for the reusable architecture is shown in Fig. 7. Three SLS / HLV launches (ranging in lift capability from $\sim 70-140 \mathrm{t}$ ) deliver the components for the ASV to LEO over a 60 day period (30 day launch centers are assumed). The crewed ASV featured in this paper is a " $0-\mathrm{g}_{\mathrm{E}}$ " in-line vehicle configuration that is assembled using an automated R\&D procedure. Artificial gravity vehicle concepts have also been evaluated and will be discussed in a future paper. The ASV's three key elements include: (1) the NTR "core" propulsion stage; (2) an integrated "saddle truss" and $\mathrm{LH}_{2}$ drop tank assembly; and (3) the crewed payload component. The crew can be launched atop the SLS or separately in the Orion/MPCV then dock with the orbiting ASV at the front end of the TransHab crew module.

Following a "2-perigee burn" trans-NEA injection (TNI) maneuver, the drained $\mathrm{LH}_{2}$ drop tank, attached to the vehicle's central saddle truss, is jettisoned and the crewed ASV coasts to the target NEA under 0- $\mathrm{g}_{\mathrm{E}}$ conditions with its PVAs tracking the Sun. Attitude control, mid-course correction and vehicle orientation maneuvers are provided by a split RCS with thrusters and bipropellant located on the rear NTR propulsion module and the short saddle truss forward adaptor ring just behind the TransHab module. After propulsively braking near the target NEA, the ASV uses the post burn "cool-down thrust" provided by its three NTR engines, together with its RCS, to rendezvous with the NEA. Two crewmembers then transfer over to the MMSEV, undock from the transfer tunnel (Fig. 8), and travel over to the NEA to begin the surface exploration and sample-gathering phase of the mission (Fig. 9). With the ASV at an appropriate standoff distance from the target NEA, multiple MMSEV sorties with rotating crews will be flown to different NEA locations to gather a diverse sampling of materials.

As the $\sim 7-30$ day stay at the target NEA draws to a close, the crew begins a period of vehicle checkout and systems verification before performing the TEI burn to begin the journey back to Earth. In the fully reusable architecture, the MMSEV is returned to Earth along with ASV. On final Earth approach, the ASV performs a braking burn and captures into a 24-hour elliptical parking orbit (500 km x 71,136 km). Post burn engine cool-down thrust is again used to assist in the return of the ASV to a LEO servicing node / propellant depot for refurbishment, resupply and reuse. The crew then enters the Orion MPCV, separates from the ASV and does a direct entry and landing on Earth. The departure dates, outbound, stay and return times for candidate human NEA missions in the late 2020 timeframe are also shown in Fig. 7. 
AIAA-2012-4209

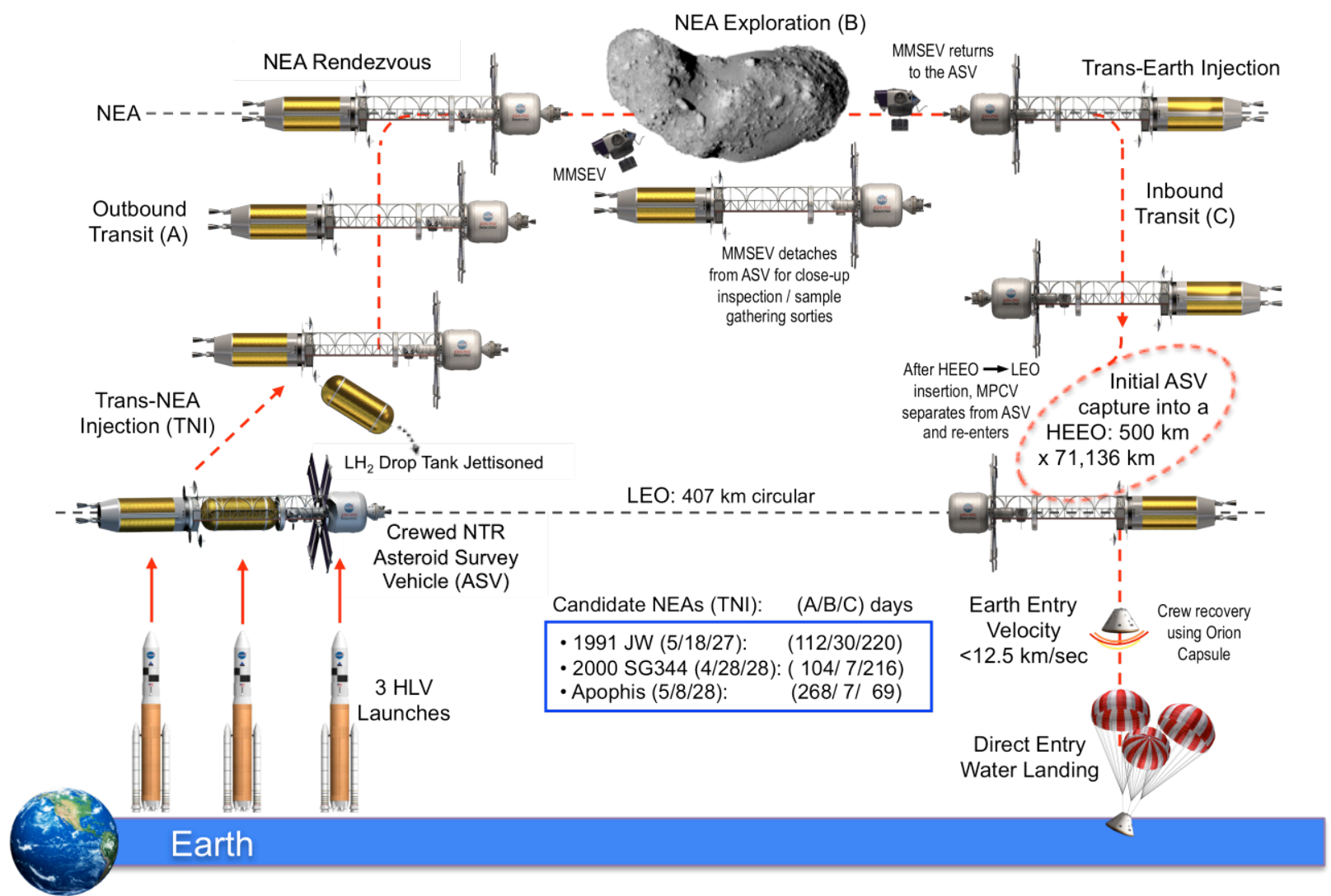

Figure 7. "Fully Reusable" Mission Scenario - ASV and MMSEV Returned to Earth Orbit

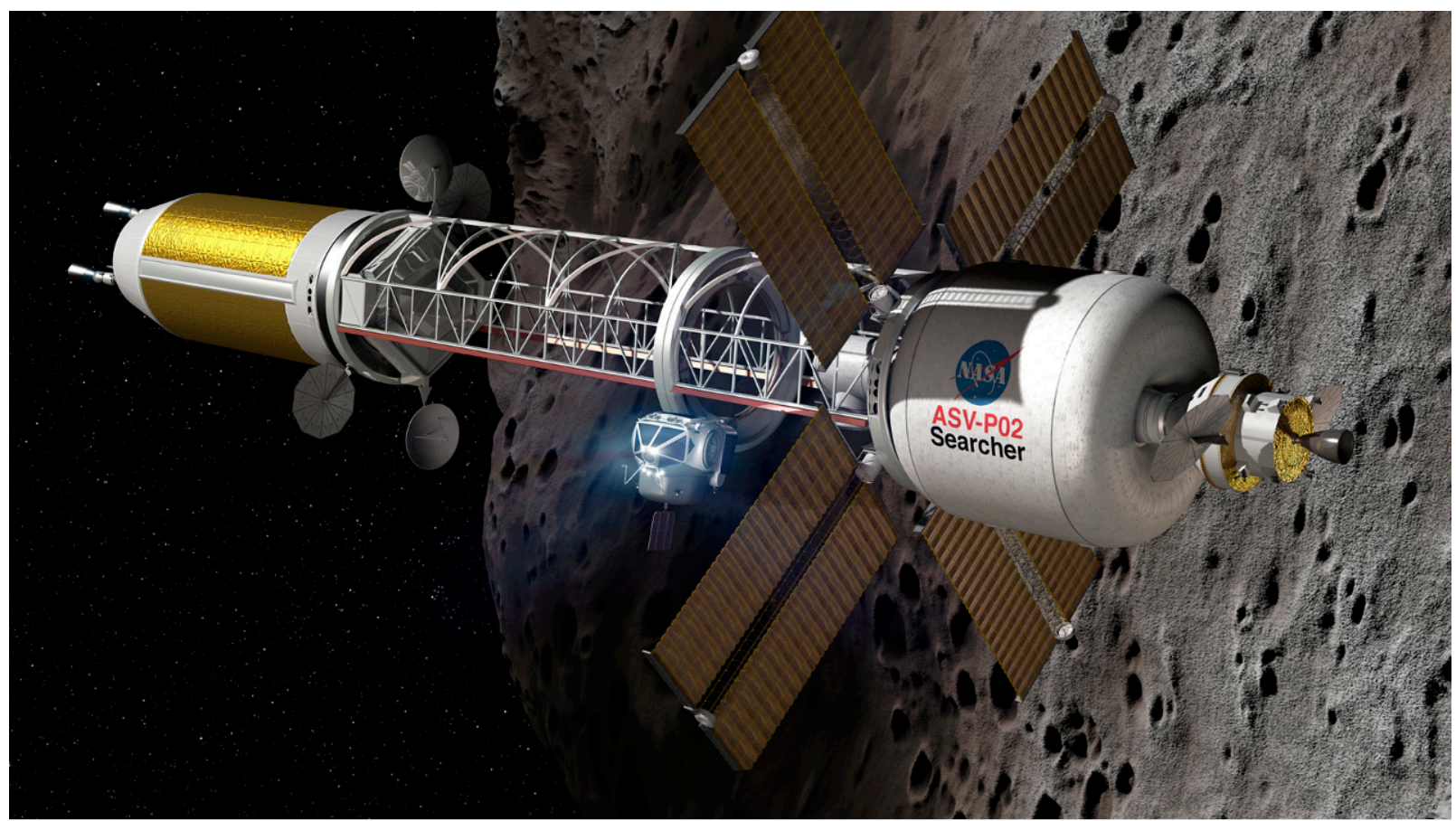

Figure 8. MMSEV Separates from ASV for Up Close NEA Examination and Sample Gathering 


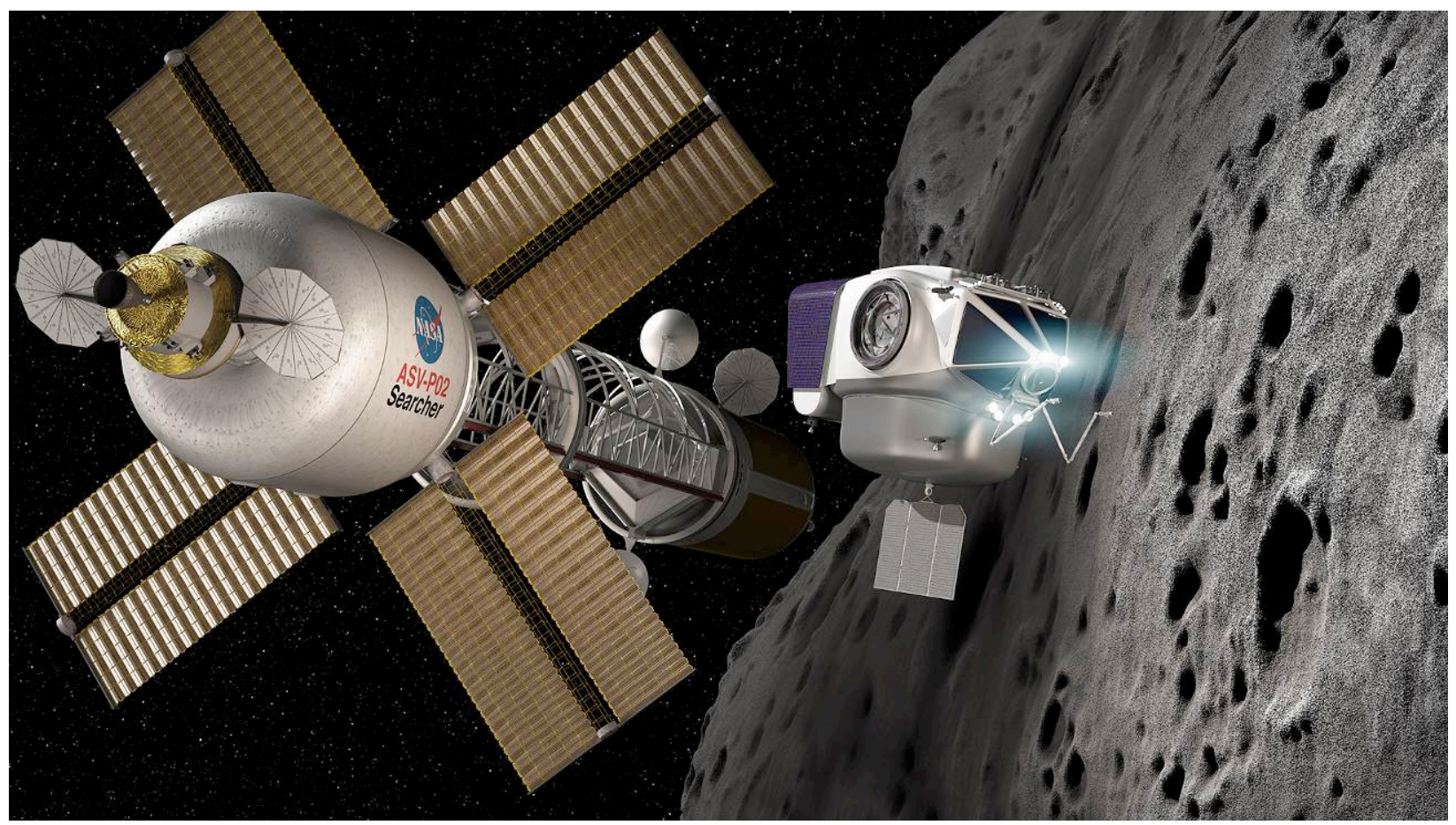

Figure 9. Options for MMSEV Use: Return to Earth or Leave at NEA for Remote Scientific Examination

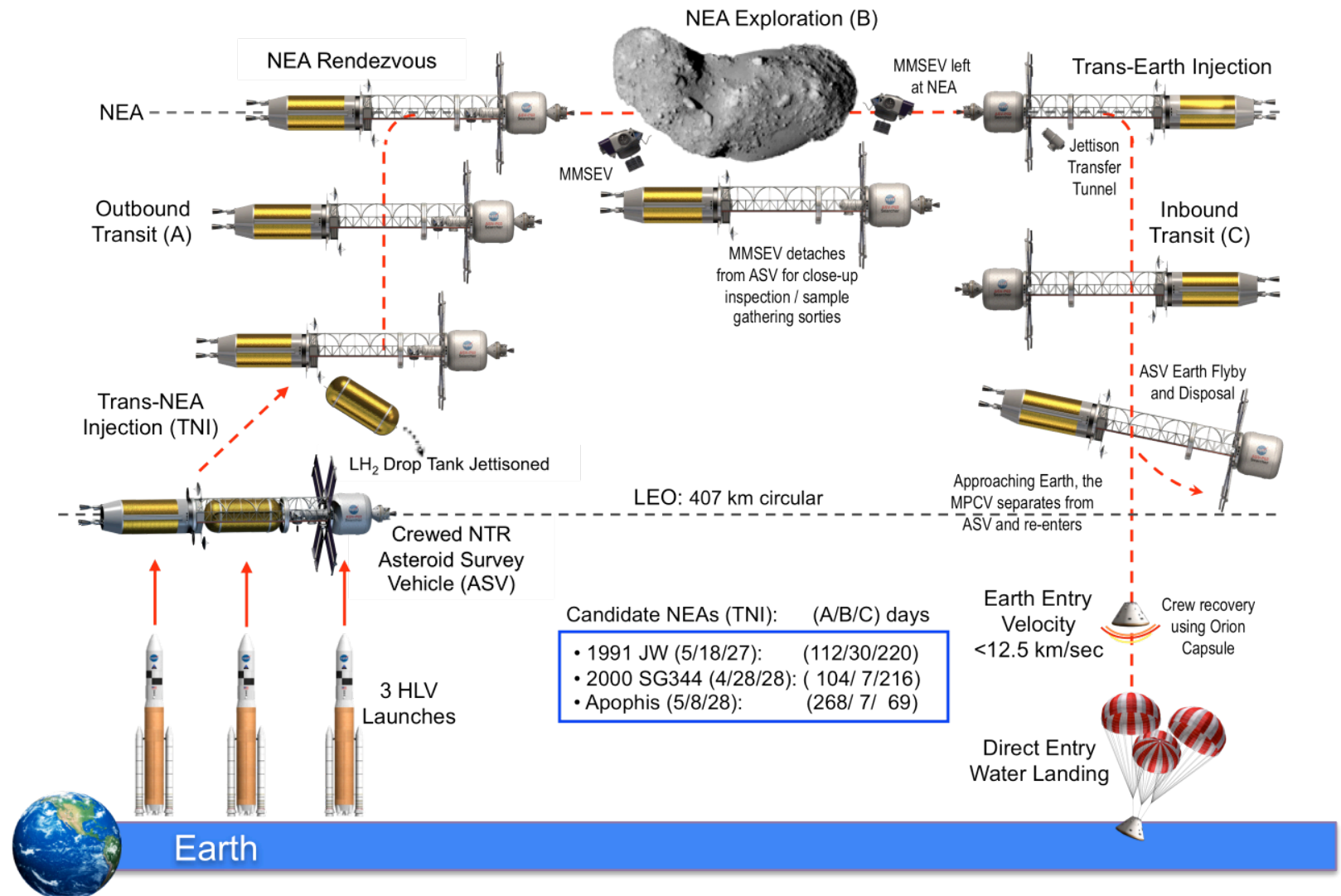

Figure 10. "Expendable" Mission Scenario - MMSEV Left at NEA, ASV Flies by Earth for Disposal 
The ConOps for the expendable mission architecture is shown in Fig. 10. In this architecture, all elements are expended in order to keep the total mission IMLEO and the size of the transportation system elements as low as possible. The MMSEV is not returned to Earth but is left at the target NEA for continued remote exploration after the crew has departed. To reduce vehicle mass and propellant requirements further, the transfer tunnel is also jettisoned before TEI. On the final approach to Earth, the crew enters the Orion MPCV, separates from the ASV and does a direct entry and landing while the ASV flies by Earth at a "sufficiently high altitude" and is disposed of into heliocentric space.

\section{Asteroid Survey Vehicle (ASV) Configuration Options for Candidate NEA Missions}

The "Copernicus / Searcher" spacecraft design illustrated in Fig. 1 has been used as the baseline configuration for assessing the benefits of using NTP for human NEA missions. Two target NEAs - both with departure dates in 2028 - have been selected for analysis in this paper. They are 2000 SG344 (a small asteroid with low energy / $\Delta \mathrm{V}$ requirements) and Apophis (a large asteroid with high energy / $\Delta \mathrm{V}$ requirements). The impact of key mission variables (like crew size, the assumed mission architecture, and launch vehicle performance - specifically available PL volume and lift capability) on vehicle size and mass has been assessed and is discussed below. Key features and component lengths for three ASV options considered for a human mission to 2000 SG344 are shown in Fig. 11.

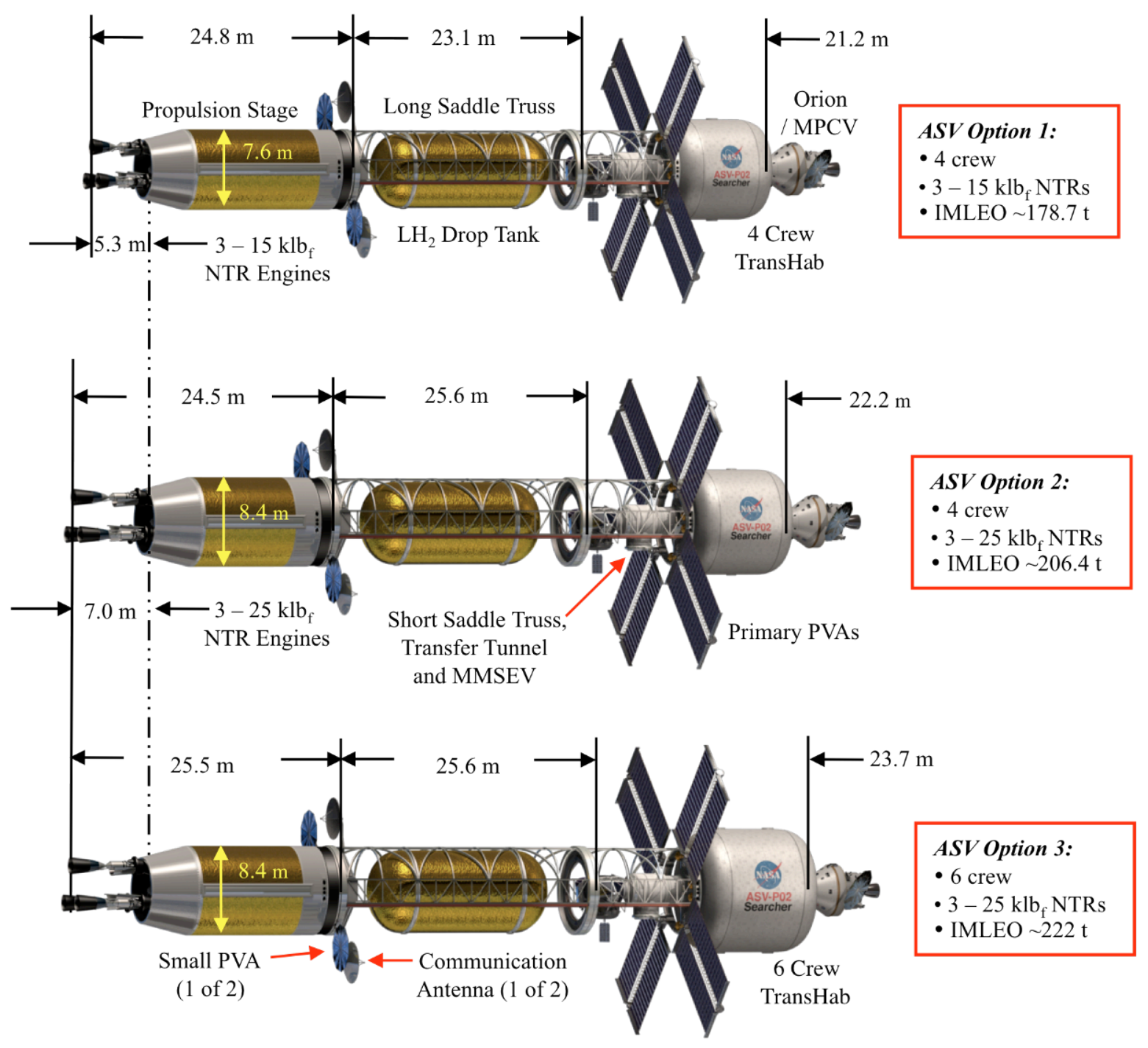

Figure 11. ASV Configuration Options for Reusable Human Mission to NEA 2000 SG344 


\section{ASV Option 1:}

Because of its low energy requirements, a human mission to 2000 SG344 with stay times of $\sim 7-28$ days can readily accomplished with a "scaled-down" version of the larger "Searcher" ASV shown in Fig. 1 that uses $10 \mathrm{~m}$ diameter $\mathrm{LH}_{2}$ tanks. Option 1 uses three smaller $15 \mathrm{klb}_{\mathrm{f}} \mathrm{NTR}$ engines on its propulsion stage rather than the baseline

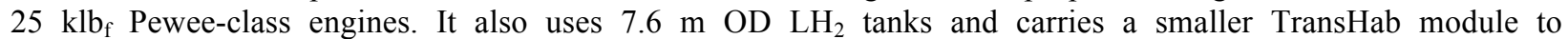
accommodate a crew of 4 . In the forward cylindrical adaptor section of all propulsion stage options is housed the RCS, avionics, batteries, deployable twin Orion-type circular PVAs, and docking system, along with a reverse turbo-Brayton cryocooler system for $\mathrm{ZBO} \mathrm{LH}_{2}$ storage. The Brayton cryocooler system mass and power requirements increase with tank diameter and are sized to remove the heat load penetrating the 60 layer MLI system while the stage is in LEO where the highest tank heat flux occurs (see Table 1). The small circular PVAs on the propulsion stage provide the electrical power for the ZBO system in LEO.

The Option 1 configuration has an IMLEO of $\sim 178.7 \mathrm{t}$ consisting of the "wet" propulsion stage $(\sim 67 \mathrm{t})$, the saddle truss and drop tank assembly $(\sim 60.7 \mathrm{t})$ and the crew PL section $(\sim 51 \mathrm{t})$. The overall vehicle length is $\sim 78 \mathrm{~m}$ which includes the Orion / MPCV at $8.9 \mathrm{~m}$. The $\mathrm{LH}_{2}$ loads in the propulsion stage and drop tank are $\sim 39.1 \mathrm{t}$ and $\sim 44.7 \mathrm{t}$, respectively. The corresponding tank lengths are $\sim 15.4 \mathrm{~m}$ and $\sim 17.4 \mathrm{~m}$. The long "saddle truss" connecting the propulsion stage and PL section is a rigid, spine-like composite structure that wraps around the upper half of the $\mathrm{LH}_{2}$ drop tank but is open underneath allowing the drained drop tank to be jettisoned during or after the TMI burn is completed. (The short saddle truss included in the PL section uses the same composite structure.) The mass of the long saddle truss scales with tank diameter and length and varies from $\sim 4.2 \mathrm{t}-8.9 \mathrm{t}$ for $7.6 \mathrm{~m}-10.0 \mathrm{~m}$ diameter tanks. The crewed PL section includes deployable rectangular PVAs used for primary power. The four PVAs shown in Fig. 11 are appropriate for Mars because of the decreased solar intensity $\left(\sim 486 \mathrm{~W} / \mathrm{m}^{2}\right)$. For NEA missions that are flown near 1 A.U. (solar intensity $\sim 1367 \mathrm{~W} / \mathrm{m}^{2}$ ), two smaller panels producing $\sim 15-30 \mathrm{~kW}_{\mathrm{e}}$ should be adequate.

Lastly, for this round trip reusable NEA mission option, there are 5 primary burns (4 restarts) that use $\sim 79.6 \mathrm{t}$ of $\mathrm{LH}_{2}$ propellant. With $45 \mathrm{klb}_{\mathrm{f}}$ of total thrust and a $\mathrm{I}_{\mathrm{sp}}$ of $906 \mathrm{~s}$, the total engine burn time for the mission is $\sim 58.9$ minutes, well under the $\sim 2$ hour accumulated engine burn time and 27 restarts demonstrated on the NERVA eXperimental Engine (the NRX-XE) in 1969. The first perigee burn during the TNI maneuver is the longest single burn in the mission at $\sim 29.8$ minutes.

\section{ASV Option 2:}

The Option 2 configuration transitions to the baseline $25 \mathrm{klb}_{\mathrm{f}}$ engine and also uses the same $8.4 \mathrm{~m} \mathrm{OD} \mathrm{Al} / \mathrm{Li} \mathrm{LH}_{2}$ tank being used for the SLS in order to maximize synergy and reduce development costs by exploiting SLS tooling, manufacturing and infrastructure. The mission is again fully reusable and carries crew of 4 . The vehicle IMLEO is $\sim 206.4 \mathrm{t}$ consisting of the "wet" propulsion stage $(\sim 77 \mathrm{t})$, the saddle truss / drop tank assembly $(\sim 77.1 \mathrm{t})$ and the crew PL section $(\sim 52.3 \mathrm{t})$. The overall vehicle length is $\sim 81.2 \mathrm{~m}$ including the Orion / MPCV. The $\mathrm{LH}_{2}$ loading in the propulsion stage and drop tank are $\sim 39.5 \mathrm{t}$ and $\sim 56.7 \mathrm{t}$, respectively, and the corresponding tank lengths are $\sim 13.2 \mathrm{~m}$ and $\sim 18.1 \mathrm{~m}$. With these tank lengths, the masses of propulsion stage and saddle truss / drop tank assembly can be balanced at $\sim 77$ t. For this reusable option, there are again 5 primary burns ( 4 restarts) and total $\mathrm{LH}_{2}$ propellant used for the mission is $\sim 91.4 \mathrm{t}$. With $75 \mathrm{klb}_{\mathrm{f}}$ of total thrust and a $\mathrm{I}_{\mathrm{sp}}$ of $906 \mathrm{~s}$, the total engine burn time for the mission is $\sim 40.6$ minutes. The first perigee burn during the TNI maneuver is again the longest single burn in the mission at $\sim 15.7$ minutes but it is almost cut in half by using the higher thrust engines.

\section{ASV Option 3:}

Option 3 is similar to Option 2 with the exception that the crew size is increased to 6 . The accompanying increase in mass for the larger TransHab and additional crew consumables leads to an $\sim 7.6 \%$ growth in IMLEO to $\sim 222 \mathrm{t}$ distributed among the three key elements as follows: (1) propulsion stage ( 81.4 t); (2) saddle truss / drop tank assembly ( $\sim 81.4 \mathrm{t}$ ); and (3) crewed PL element ( $\sim 59.1 \mathrm{t})$. The vehicle length grows to $\sim 83.7 \mathrm{~m}$ including the Orion / MPCV. The $\mathrm{LH}_{2}$ loading in the propulsion stage and drop tank increase to $\sim 43.2 \mathrm{t}$ and $\sim 60.5 \mathrm{t}$, respectively, and the corresponding tank lengths are $\sim 14.3 \mathrm{~m}$ and $\sim 19.1 \mathrm{~m}$. With these tank lengths, the masses of propulsion stage and saddle truss / drop tank assembly are again balanced at $\sim 81.4 \mathrm{t}$. As before, there are 5 primary burns ( 4 restarts) in this reusable architecture and the usable $\mathrm{LH}_{2}$ propellant load is $\sim 98.5 \mathrm{t}$. The total engine burn time for the mission is $\sim 43.7$ minutes and the longest single burn in the mission is $\sim 17$ minutes, again for the first perigee burn. In the recent NEA architecture analyses performed by Drake [7], a 10\% performance margin and $2.5 \%$ adaptor mass allowance was levied against a $100 \mathrm{t}$ SLS resulting in a net launch capability to LEO of $\sim 87.8 \mathrm{t}$. Using NTP, the mission planner not only has an additional mass margin of $\sim 6.4 \mathrm{t}$ to work with but also has the opportunity to design a reusable mission architecture as well. 


\section{ASV Option 4 (Expendable Mission to Apophis):}

The Option 4 ASV configuration shown in Figs. 12, 13 and 14 is sized for a 344-day expendable mission to the large NEA "Apophis" with a crew of 4 . With an estimated diameter of $\sim 270-350 \mathrm{~m}$, Apophis is $\sim 5-10$ times larger than 2000 SG344. A notional size comparison between it and ASV Option\#4 is shown Fig. 12. Like Option $\# 2$, it uses three clustered $25 \mathrm{klb}_{\mathrm{f}}$ engines and $8.4 \mathrm{~m} \mathrm{OD} \mathrm{LH}_{2}$ propellant tanks for both the propulsion stage and drop tank. Because of Apophis' higher $\Delta \mathrm{V}$ requirement, the ASV's drop tank is drained after the first perigee burn and is then jettisoned. In the expendable mission architecture assumed for Option 4, the core propulsion stage provides the propellant to perform the second perigee burn plus the Apophis braking and TEI maneuvers that follow.

The vehicle IMLEO is $\sim 221.3 \mathrm{t}$ consisting of the "wet" propulsion stage ( $94.1 \mathrm{t})$, the saddle truss / drop tank assembly $(\sim 74.9 \mathrm{t})$ and the crew PL section $(\sim 52.3 \mathrm{t})$. The overall vehicle length is $\sim 84.4 \mathrm{~m}$ including the Orion / MPCV (shown in Fig. 14). The $\mathrm{LH}_{2}$ tanks lengths are the same for both the propulsion stage and the drop tank at $\sim 16.4 \mathrm{~m}$ and each contains $\sim 50.7 \mathrm{t}$ of $\mathrm{LH}_{2}$ propellant.

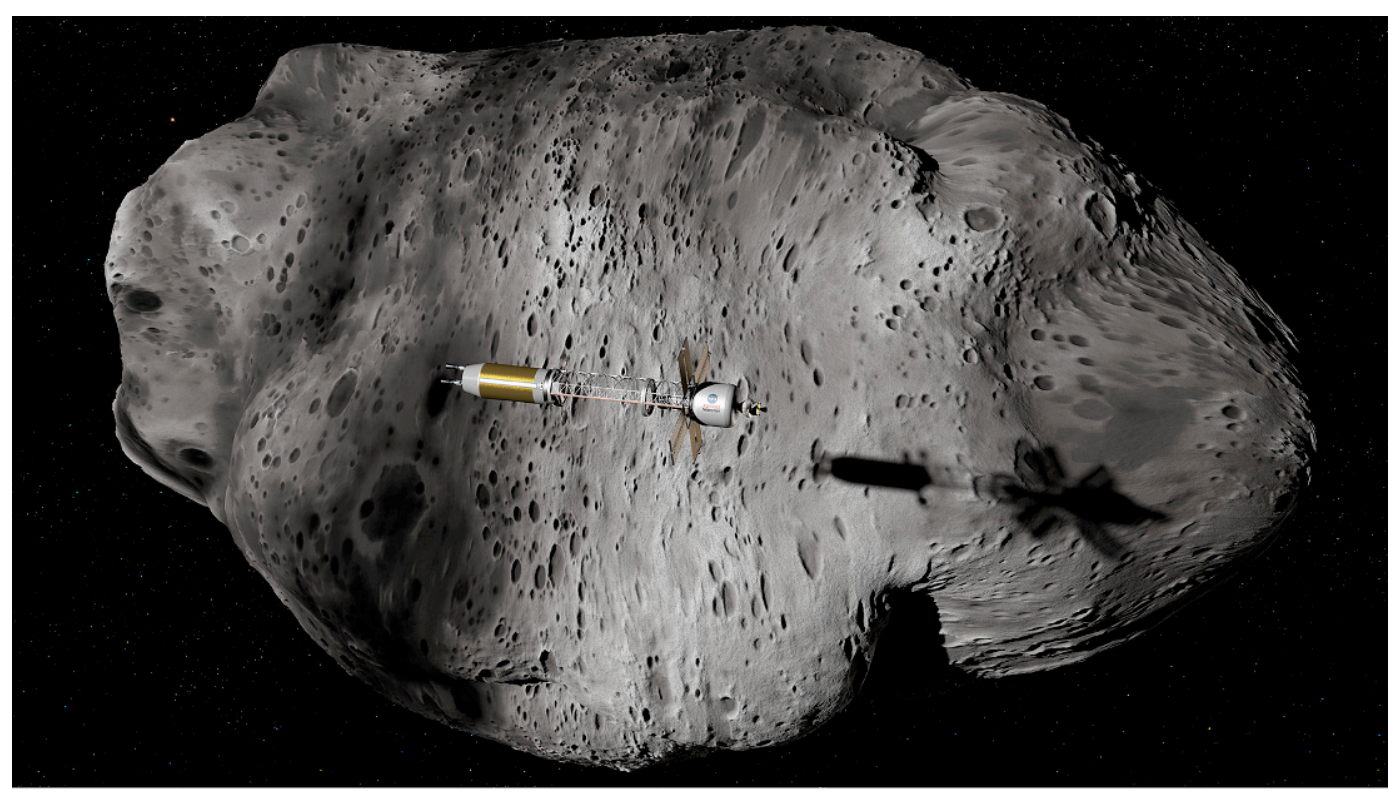

Figure 12. Size Comparison of ASV Option 4 and a Notional 300 m Long NEA

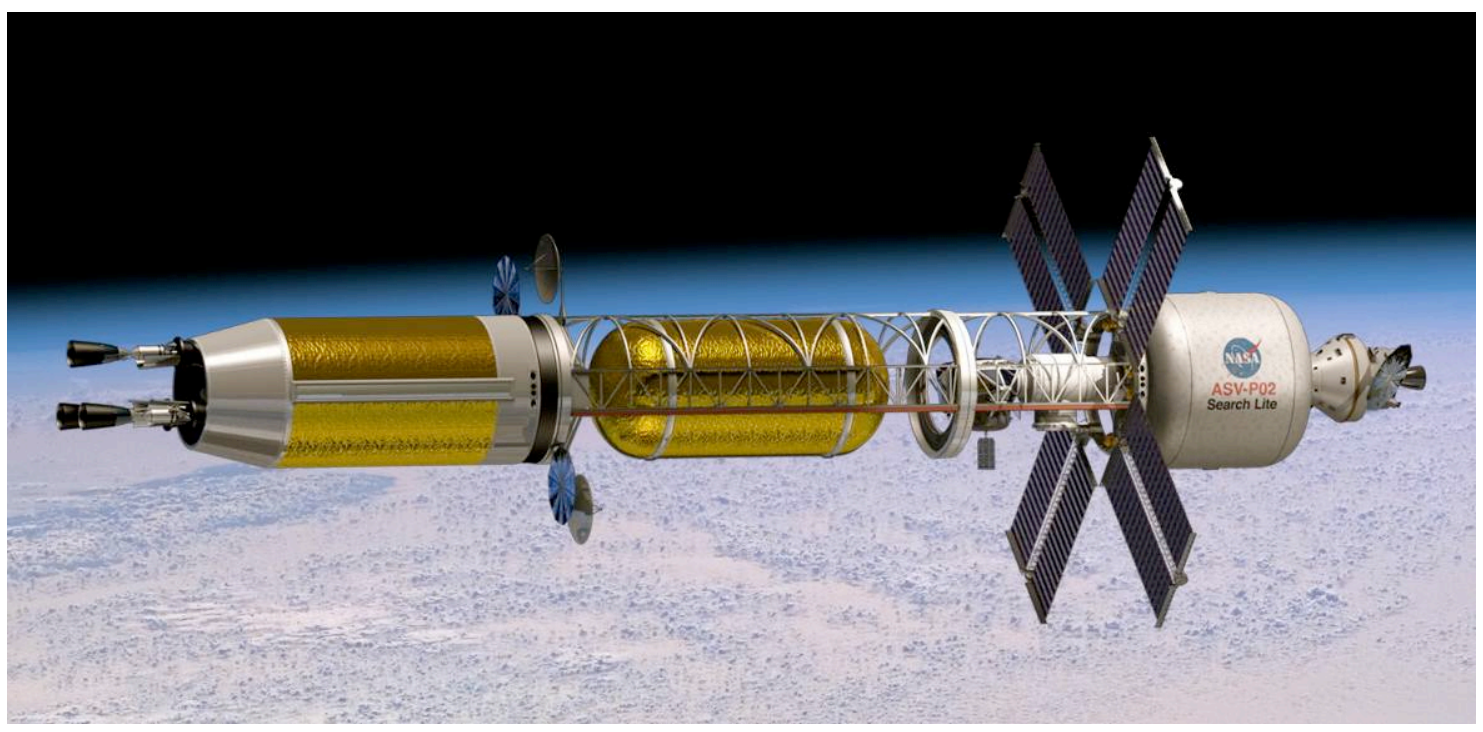

Figure 13. ASV Option 4 Can Support Human Missions to 2000 SG344 or Apophis in 2028 
In an expendable mission to Apophis there are 4 primary burns and 3 engine restarts. The total $\mathrm{LH}_{2}$ propellant used in the mission is $\sim 95.2 \mathrm{t}$ and the total engine burn time is $\sim 42.2$ minutes. The first perigee burn provides $\sim 2 / 3^{\text {rd }}$ of total $\Delta \mathrm{V}$ required for the TNI maneuver and it is therefore the longest at $\sim 24.2$ minutes.

An attractive feature of ASV Option 4 (illustrated in Fig. 13) is its ability to support a human mission to either Apophis or 2000 SG344 both of which would depart LEO in 2028 within eleven days of each other (see Table 1). Because the higher-energy Apophis mission determines the ASV propulsion stage and drop tank propellant capacities, it has significant capability that can readily support a reusable mission to 2000 SG344 with its lower energy requirement. The IMLEO for this mission is $\sim 217.6 \mathrm{t}$ which includes the "wet" propulsion stage $(\sim 92.3 \mathrm{t})$, the saddle truss / drop tank assembly $(\sim 72.7 \mathrm{t})$ and the crew PL section $(\sim 52.6 \mathrm{t})$. The overall vehicle length and $\mathrm{LH}_{2}$ tanks lengths are the same at $\sim 84.4 \mathrm{~m}$ and $\sim 16.4 \mathrm{~m}$, respectively. The propulsion stage and drop tanks are however slightly off-loaded at $\sim 96.4 \%$ and carry $\sim 48.9 \mathrm{t}$ of propellant. The drop tank is jettisoned after the 2-perigee burn TNI maneuver is completed. The propulsion stage supplies the propellant for approximately half of the second perigee burn and all the remaining propulsion maneuvers after that.

Similar to Option 2, there are 5 primary burns and 4 restarts required for this mission. The total $\mathrm{LH}_{2}$ propellant used is $\sim 93 \mathrm{t}$ and the total engine burn time is $\sim 41.3$ minutes. The first perigee burn is again the longest single burn at $\sim 16$ minutes.

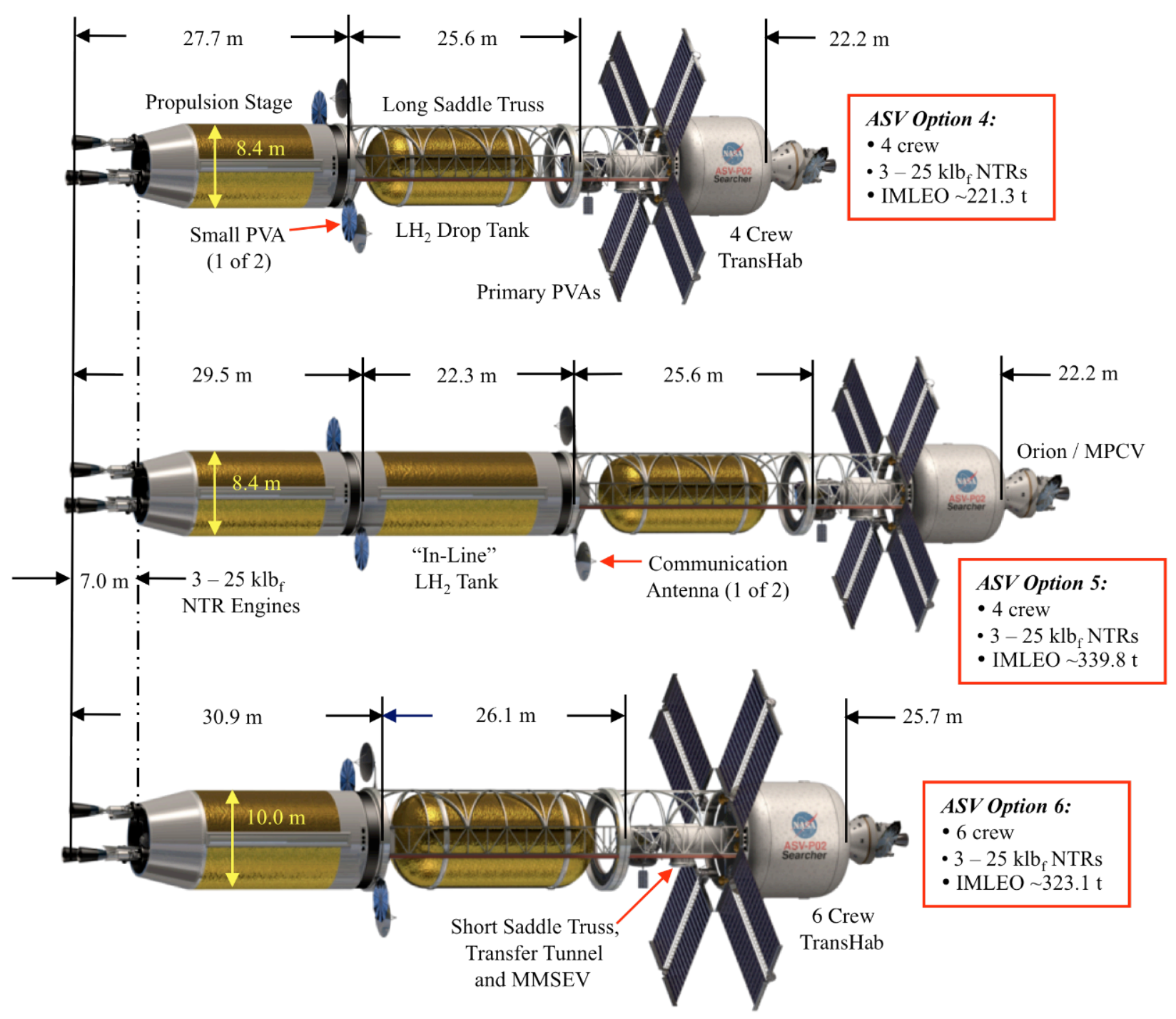

Figure 14. ASV Configuration Options for Expendable and Reusable Human Missions to Apophis 


\section{ASV Option 5 (“4 - Element” Reusable Mission to Apophis):}

Key features and component lengths for two other ASV options considered for a human mission to Apophis are also shown in Fig. 14. Like Options 2 - 4, Option 5 uses $25 \mathrm{klb}_{\mathrm{f}}$ engines, $8.4 \mathrm{~m}$ OD tanks and carries a crew of 4. It requires an additional "in-line" $\mathrm{LH}_{2}$ tank, however, because the drop tank and propulsion stage do not have sufficient propellant capacity. This 4-element vehicle has an IMLEO of $\sim 339.8 \mathrm{t}$ that includes the propulsion stage ( $\sim 99.8 \mathrm{t})$, in-line propellant tank ( $\sim 91.5 \mathrm{t})$, saddle truss / drop tank assembly ( $\sim 93.4 \mathrm{t})$, and the crew PL section $(\sim 55.1 \mathrm{t})$. The overall vehicle length is $\sim 108.5 \mathrm{~m}$ including the Orion / MPCV. The in-line and drop tanks have the same length $(\sim 20.3 \mathrm{~m})$ and carry the same propellant load $(\sim 64.8 \mathrm{t})$. The propulsion stage tank length is $\sim 18.3 \mathrm{~m}$ and it carries $\sim 57.4 \mathrm{t}$ of $\mathrm{LH}_{2}$ propellant. Although this reusable mission still has 5 primary burns (4 restarts), the total usable $\mathrm{LH}_{2}$ propellant requirement increases to $\sim 176.1 \mathrm{t}$ because of the larger starting mass in LEO and the addition of the in-line tank structure to the vehicle dry mass. The total engine burn time for the mission is $\sim 78.2$ minutes. The first perigee burn provides $\sim 2 / 3^{\text {rd }}$ of total $\Delta \mathrm{V}$ required for TNI and is the longest single burn at $\sim 38.6$ minutes. After this burn, the drop tank is drained and subsequently jettisoned to reduce vehicle mass and propellant consumption during the second burn. The in-line tank and propulsion stage supply the propellant for all follow-on burns.

\section{ASV Option 6 ("3 - Element" Reusable Mission to Apophis):}

Option 6 is the Copernicus spacecraft from Mars DRA 5.0 configured for reusable NEA missions to $1991 \mathrm{JW}$ in 2027 or Apophis in 2028. It uses a three $25 \mathrm{klb}_{\mathrm{f}}$ NTR engines, has $10 \mathrm{~m}$ diameter $\mathrm{LH}_{2}$ tanks and carries a crew of 6. The trajectory details and $\Delta \mathrm{V}$ budget for $1991 \mathrm{JW}$ are shown in Fig. 15. The Apophis mission, however, is slightly more demanding with a total mission $\Delta \mathrm{V}$ of $\sim 7.378 \mathrm{~km} / \mathrm{s}$. It requires an IMLEO of $\sim 323.2 \mathrm{t}$ which includes the propulsion stage $(\sim 138.1 \mathrm{t})$, the saddle truss and $\mathrm{LH}_{2}$ drop tank $(\sim 122.9 \mathrm{t})$, and the crew PL section $(\sim 62.2 \mathrm{t})$. The overall vehicle length is $\sim 91.6 \mathrm{~m}$ including the Orion / MPCV. During launch, the engines have a portion of their nozzle $(\sim 2.2 \mathrm{~m})$ retracted so the propulsion stage length is $\sim 28.7 \mathrm{~m}$. Once in orbit, the nozzles are extended and the propulsion stage length increases to $\sim 30.9 \mathrm{~m}$. The tank lengths for the propulsion stage and drop tank are $\sim 19.7 \mathrm{~m}$ and $\sim 21.1 \mathrm{~m}$, respectively. Their corresponding propellant loads are $\sim 87.2 \mathrm{t}$ and $\sim 93.9 \mathrm{t}$ for a maximum $\mathrm{LH}_{2}$ capacity of $\sim 181.7 \mathrm{t}$. For the Apophis mission, the $\mathrm{LH}_{2}$ propellant load is $\sim 181.1 \mathrm{t}$ (near maximum capacity). The total $\mathrm{LH}_{2}$ propellant used in the mission is $\sim 171.7 \mathrm{t}$ and the total engine burn time is $\sim 76.2$ minutes. The first perigee burn again provides $\sim 2 / 3^{\text {rd }}$ of total $\Delta \mathrm{V}$ required for TNI and is the longest single burn at $\sim 38$ minutes. For $1991 \mathrm{JW}$, the IMLEO is $\sim 316.7 \mathrm{t}$, the $\mathrm{LH}_{2}$ propellant loading is $\sim 175.2 \mathrm{t}(\sim 96.4 \%$ of the maximum capacity) and the total engine burn time is $\sim 73.8$ minutes with 4 restarts required.

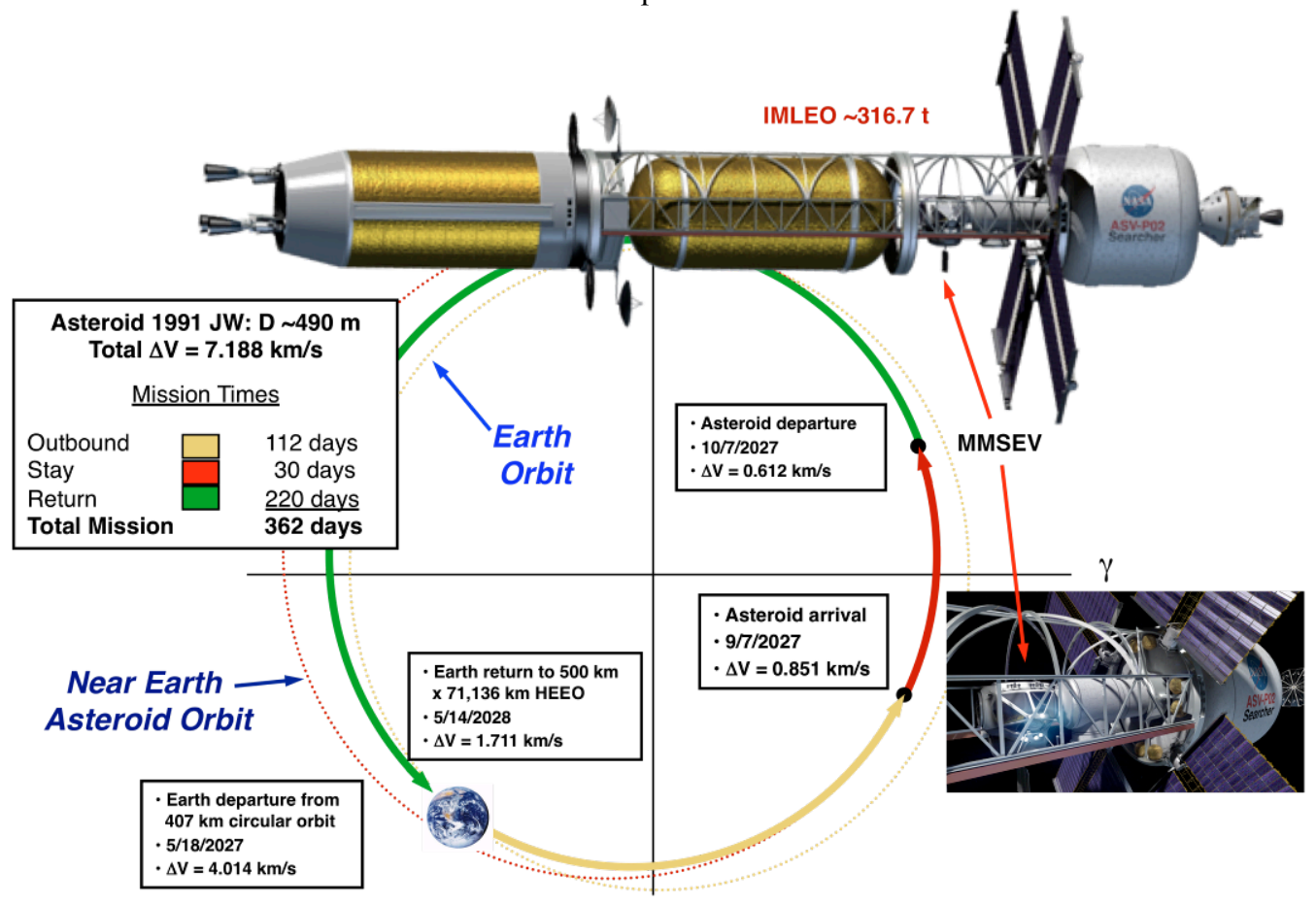

Figure 15. Trajectory Details for Reusable Mission to 1991 JW Using ASV Option 6 


\section{Notional Plans for NTP Technology Development and Demonstration}

In FY'11, NASA started a technology development effort in NTP under the Advanced In-Space Propulsion (AISP) component of its Exploration Technology Development and Demonstration (ETDD) program. The NTP effort included two key tracks: "Foundational Technology Development" followed by "Technology Demonstration" projects (details shown in Fig. 16). Near-term activities initiated under Foundational Technology Development (now part of NASA's Nuclear Cryogenic Propulsion Stage (NCPS) project [14]), included five key tasks and objectives:

Task 1. Mission Analysis, Engine/Stage System Characterization and Requirements Definition to help establish performance goals for fuel development and guide concept designs for small, scalable demonstration engines and the full size engines needed for future human NEA and Mars missions;

Task 2. NTP Fuels and Coatings Assessment and Technology Development aimed at recapturing fabrication techniques, maturing and testing fuel, then selecting between the two primary fuel forms previously identified by DOE and NASA - NERVA "composite" and $\mathrm{UO}_{2}$ in tungsten "cermet" fuel [15]. Partial, then full-length fuel elements will be tested in the NTR Element Environmental Simulator (NTREES) [16] at the MSFC using up to $\sim 1.2$ MW of RF heating to simulate the NTP thermal environment that includes exposure to hot $\mathrm{H}_{2}$. Candidate fuels and fuel element designs will be screened in NTREES prior to irradiation testing and final selections;

Task 3. Engine Conceptual Design, Analysis, and Modeling aimed at developing conceptual designs of small demonstration engines and the full size $25 \mathrm{klb}_{\mathrm{f}}$-class engines utilizing the candidate fuels discussed above. State-ofthe-art numerical models are being used to determine reactor core criticality, detailed energy deposition and control rod worth within the reactor subsystem [17], provide thermal, fluid and stress analysis of fuel element geometries [18], and predict engine operating characteristics and overall mass [19];

Task 4. Demonstration of Affordable Ground Testing focused on "proof-of-concept" validation of the SAFE (Subsurface Active Filtration of Exhaust) [20] or "bore-hole" test option at the Nevada Test Site (NTS). Nonnuclear, subscale hot gas injection tests, some with a radioactive tracer gas, will be conducted in a vertical bore-hole

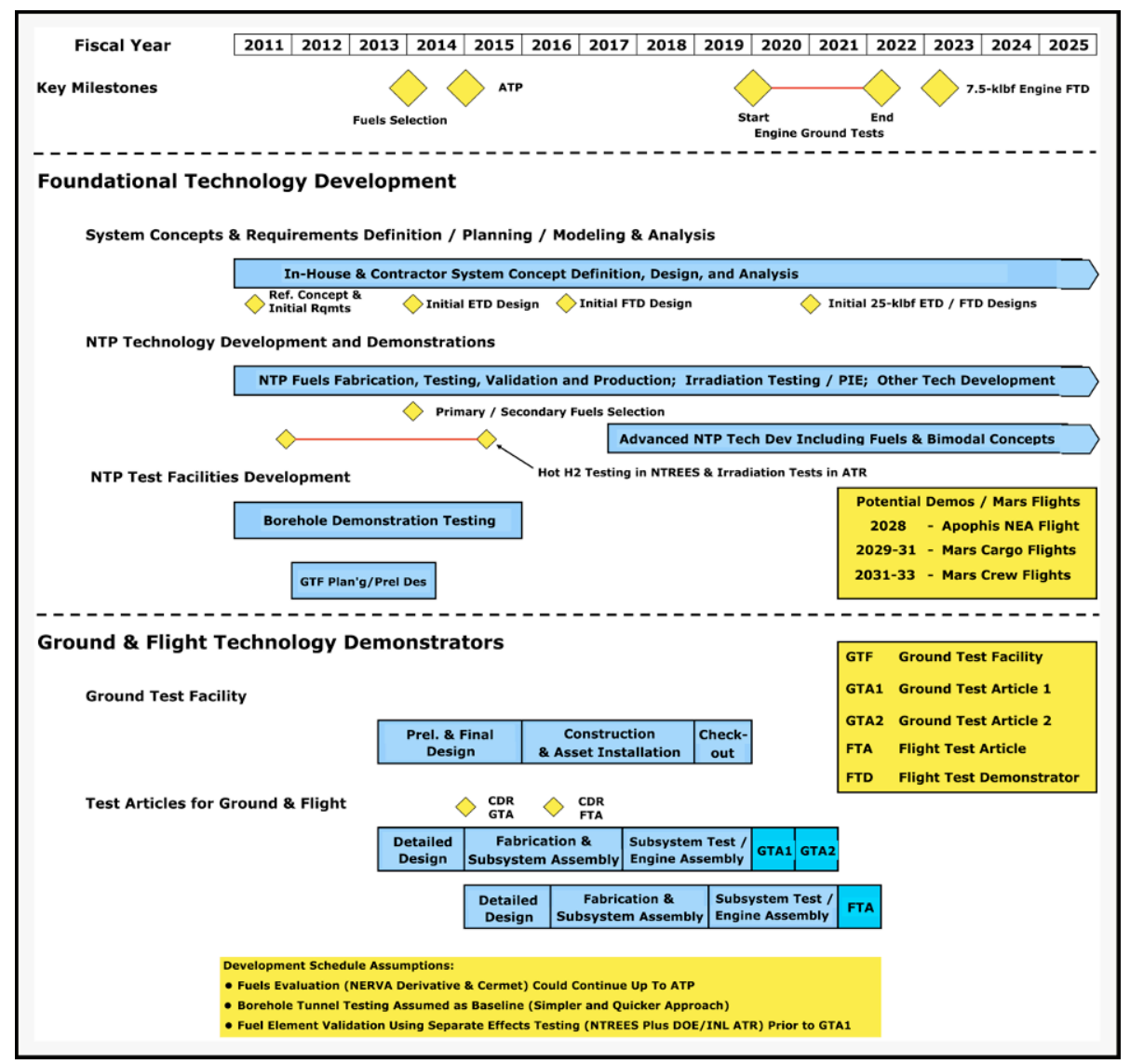

Figure 16. Notional NTP Development Plan includes Foundational, Ground and Flight Technology Demonstrations. 
to obtain valuable test data on the effectiveness of the porous rock (alluvium) to capture, holdup and filter the engine exhaust. The data will also help calibrate design codes needed by DOE to design the SAFE test facility and support infrastructure needed for the small engine ground technology demonstration tests and the larger $25 \mathrm{klb}_{\mathrm{f}}$-class engine tests to follow; and

Task 5. Formulation of an Affordable and Sustainable NTP Development Strategy aimed at outlining the content of an affordable development plan that utilizes separate effects tests (e.g., NTREES and irradiation tests), existing assets and innovative SAFE testing at the NTS, and small scalable engines for ground and flight technology demonstrations.

The above tasks, successfully carried out over the next 3 years under the NCPS project, could provide the basis for "authority to proceed" (ATP) in 2015 with ground technology demonstration (GTD) tests at the NTS in late 2019 , followed by a flight technology demonstration (FTD) mission in 2023. To reduce development costs, the GTD and FTD tests would use a small, low thrust $\left(\sim 6.5-7.5 \mathrm{klb}_{\mathrm{f}}\right)$ engine with a "common" fuel element design that is scalable to higher thrust levels by increasing the number of elements in a larger diameter core producing a greater thermal power output. The GTD effort would test two ground test articles (GTA1, GTA2) and one flight test article (FTA) that provide system-level technology demonstration and design validation for a follow-on FTD mission.

The small engine ground and flight demonstration tests would also maximize the use of existing and proven liquid rocket components to further ensure affordability. A small NTP FTD could fit within the 5-meter fairing of the Delta 4 M $(5,4)$ launch system (shown in Fig. 17) and leverage a lot of DCSS components like the hydrogen tank, systems for pressurization, attitude control, avionics and power, plus inter-stage and thrust structure [21, 22]. The hydrogen tank's cylindrical barrel section would be increased to accommodate the propellant needed for the mission. For a robotic precursor flight to $2000 \mathrm{SG} 344$, a small NTP stage $(\sim 3 \mathrm{t})$ with a propellant loading of $\sim 6.5 \mathrm{t}$ can deliver $\sim 4.1 \mathrm{t}$ of payload. With a small $7 \mathrm{klb}_{\mathrm{f}}$ engine, an $\mathrm{I}_{\mathrm{sp}}$ of $\sim 905 \mathrm{~s}$ and $\sim 6.2 \mathrm{t}$ of $\mathrm{LH}_{2}$ propellant needed for the two primary burns, the total engine burn time is $\sim 29.5$ minutes.

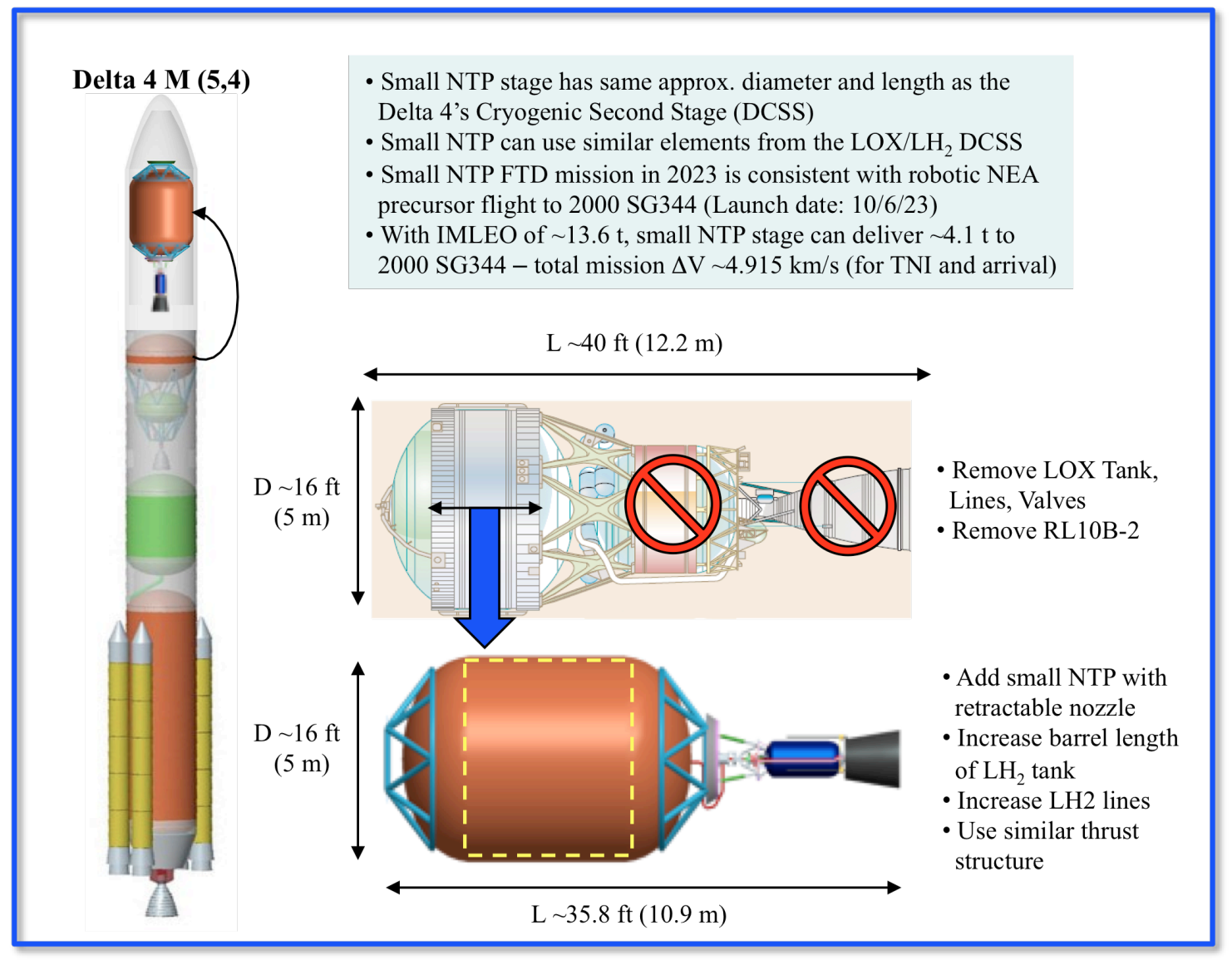

Figure 17. Small NTP Stage Launched on Delta 4 M $(5,4)$ Could Validate NTR / Stage Hardware and Support a Robotic Precursor Flight to 2000 SG344 in Late 2023 Timeframe. 
The FTD will also provide the technical foundation for an "accelerated approach" to design, fabrication, ground and flight testing of the fill-size $25 \mathrm{klb}_{\mathrm{f}}$-class engine by $\sim 2026$. The Rover program used a common fuel element/tie tube design and similar approach to test the $50 \mathrm{klb}_{\mathrm{f}}$ Kiwi-B4E, the $75 \mathrm{klb}_{\mathrm{f}}$ Phoebus-1B, the $250 \mathrm{klb}_{\mathrm{f}}$ Phoebus-2A, and $25 \mathrm{klb}_{\mathrm{f}}$ Pewee engines, in that order, between 1964 and 1968. Flight testing a stage with clustered $25 \mathrm{klb}_{\mathrm{f}}$ engines would follow next in time to support 1-year round trip human NEA missions in the late 2020's followed by short round trip / short orbital stay Mars missions in the early 2030's [6].

\section{Summary and Conclusions}

The Global Exploration Roadmap developed by NASA and 13 other space agencies through the ISECG identified the "Asteroid Next" path as one of the two possible pathways for future human exploration after the utilization phase of ISS is completed. The "Asteroid Next" path has as its focus a first human NEA mission in 2028 necessitating the development and demonstration of key in-space exploration technologies and capabilities necessary for traveling through and living in deep space. Advanced propulsion is one of those key technologies. This paper shows the benefits of NTP for future human NEA missions. Parametric analysis by Drake [7] also indicates NTP superiority over other propulsion options allowing access to more NEAs over a larger range of sizes and round trip times with fewer HLVs required.

The NTR represents the next major evolutionary step in high performance liquid rocket propulsion. It was developed to a high TRL in twenty rocket / reactor tests that demonstrated a wide range of thrust levels, hightemperature fuel, sustained engine operation, accumulated time at full power, and restart capability - everything required for a human NEA mission. With its high thrust and high specific impulse (twice that of chemical propulsion), NTP has consistently been identified as the "preferred propulsion option" for human Mars missions. Compared to chemical propulsion, the use of NTP in NASA's recent Mars DRA 5.0 study, helped reduce the required launch mass by over $400 \mathrm{t}$ - the equivalent mass of the ISS. Also, in contrast to other advanced propulsion options, NTP requires no large technology or performance scale-ups. In fact, the smallest engine tested during the Rover program - the $25 \mathrm{klb}_{\mathrm{f}}$ "Pewee" engine is sufficient for Mars when used in a clustered engine arrangement.

The "Copernicus" crewed MTV design developed for DRA 5.0 was sized to allow it to perform all of the fastconjunction Mars mission opportunities over the 15-year synodic cycle. It therefore has significant capability that can be utilized for a variety human NEA missions currently under study by NASA. Examined in this paper are lowenergy missions to small asteroids (2000 SG344 in 2028), as well as, high-energy missions to larger asteroids (1991 JW in 2027 and Apophis in 2028). Apophis is of particular interest because of its large size and its close approach to Earth in 2029. Outfitted as an ASV, the "Copernicus / Searcher" spacecraft design (ASV Option 6) can perform fully reusable missions with a crew of 6 to either $1991 \mathrm{JW}$ or Apophis. For Apophis, the required IMLEO, launch vehicle lift capability and total engine burn time are $\sim 323.1 \mathrm{t}, \sim 140 \mathrm{t}$, and $\sim 76.2$ minutes, respectively.

Reconnaissance missions to either of these NEAs can serve as a "check out" mission of Copernicus' key elements (its propulsion stage, TransHab and life support systems, etc.) in a "deep space" environment prior to undertaking a longer duration Mars orbital mission. The Apollo 8 orbital mission of the Moon in December 1968 provided a similar check out for the Apollo Command and Service module and its primary propulsion system. Human NEA missions can also provide valuable scientific data on asteroid composition plus experience in proximity operations needed for extracting future resources or for executing potential threat mitigation techniques against a possible Earth impacting NEA.

The impact of crew size, assumed mission scenario (expendable versus reusable), and SLS / HLV capability (specifically launch mass and usable payload volume) on ASV design has also been quantified. For a low-energy mission to 2000 SG344 in 2028, a reusable mission scenario with a crew of 4 is possible using three 70 t-class SLS launches (ASV Option 1), $3-15 \mathrm{klb}_{\mathrm{f}}$ engines, and $7.6 \mathrm{~m}$ diameter $\mathrm{LH}_{2}$ propellant tanks. The IMLEO and total engine burn time are $\sim 178.7 \mathrm{t}$ and $\sim 58.9$ minutes, respectively.

A "scaled-down" version of the larger Copernicus / Searcher-class ASV, called "Search Lite" (Fig. 13) uses the same $25 \mathrm{klb}_{\mathrm{f}}$ engines but smaller $8.4 \mathrm{~m}$ diameter $\mathrm{LH}_{2}$ tanks like that used on SLS. Search Lite can perform the Apophis mission with 4 crewmembers in the "expendable mode" for an IMLEO of $\sim 221 \mathrm{t}$. The maximum lift required is $\sim 94 \mathrm{t}$ for the "wet" propulsion stage and the total engine burn time for the mission is $\sim 42$ minutes. For $\sim 218$ t, the Search Lite ASV can also perform a fully reusable mission to 2000 SG344 with a crew of 4.

Lastly, NASA has initiated Foundational Technology Development work on NTP in a number of key areas under the NCPS project. If successful, this effort could be followed by system-level Technology Demonstrations that include ground testing a small, scalable NTR by 2020 , followed by a flight test in 2023 . A robotic precursor mission to 2000 SG344 in late 2023 could provide an attractive FTD opportunity for a small NTP stage that can deliver significant payload for gathering the scientific data needed for planning a human mission 5 years later. 
AIAA-2012-4209

\section{Acknowledgments}

The authors express their thanks to Chris Moore and John Warren (NASA/HQ), John Taylor and Tim Wickenheiser (GRC), and Bret Drake (JSC) for their encouragement and support of this work. The author (SKB) also expresses his thanks to Bob Sauls (John Frassanito \& Associates, Inc.) for artwork depicted in this paper.

\section{References}

[1] The Global Exploration Roadmap, National Aeronautics and Space Administration, NP-2011-09-766-HQ, Washington, DC, September 2011.

[2] National Space Policy of the United States, June 28, 2010, pg.11.

[3] Human Exploration of Mars Design Reference Architecture 5.0, Drake, Bret G., ed., National Aeronautics and Space Administration, NASA-SP-2009-566, Washington, DC, July 2009.

[4] Koeing, D. R., "Experience Gained from the Space Nuclear Rocket Programs (Rover / NERVA)," Los Alamos National Laboratory, Report LA-10062-H, Los Alamos, NM, May 1986.

[5] Borowski, S. K., McCurdy, D. R., and Packard, T. W., "7-Launch NTR Space Transportation System for NASA's Mars Design Reference Architecture (DRA) 5.0", AIAA-2009-5308, August 2009.

[6] Borowski, S. K., McCurdy, D. R., and Packard, T. W., "Nuclear Thermal Rocket (NTR) Propulsion: A Proven Game-Changing Technology for Future Human Exploration Missions", GLEX-2012.09.4.6x12341, Global Space Exploration Conference, Washington, DC, May 2012.

[7] Drake, B. G., "Strategic Considerations of Human Exploration of Near Earth Asteroids", IEEEAC paper \#1069, IEEE Aerospace Conference, Big Sky, MT, March 2012.

[8] Asphaug, E., "Growth and Evolution of Asteroids", Annual Review of Earth and Planetary Sciences, January 22, 2009, pgs. 413-448.

[9] "NASA Refines Asteroid Apophis' Path Toward Earth", National Aeronautics and Space Administration, October 7, 2009, http://www.nasa.gov/home/hqnews/2009/oct/HQ_09-232_Apophis_Update.html

[10] Taub, J. M., "A Review of Fuel Element Development for Nuclear Rocket Engines", Los Alamos National Laboratory, Report LA-5931, Los Alamos, NM, June 1975.

[11] Kruger, G. B., "710 High Temperature Gas Reactor Program Summary Report", GEMP-600, General Electric, Cincinnati, OH, September 1973.

[12] Marchaterre, J. F., et al., "Nuclear Rocket Program Terminal Report", ANL-7236, Argonne National Laboratory, Argonne, IL, February 1968.

[13] Schnitzler, B. G., Borowski, S. K., and Fittje, J. E., "25,000-lbf Thrust Engine Options Based on the Small Nuclear Rocket Engine Design", AIAA-2009-5239, August 2009.

[14] Houts, M. G., et al., "Nuclear Cryogenic Propulsion Stage", Nuclear and Emerging Technologies for Space (NETS) - 2012 Conference, paper \#3093, The Woodlands, TX, March 2012.

[15] Burkes, D. Wachs, D., Werner, J., (DOE/INL), Bell, G., Miller, J., Papano, P., (DOE/ORNL), and Borowski, S. K., (NASA/GRC), "The Rationale and Justification for Selection of Carbide "Composite" and Ceramic Metallic "Cermet" NTP Fuel Options", a Joint DOE / NASA White Paper for NASA HQ, May 2007.

[16] Emrich, William J., and Kirk, Daniel R., "Design Considerations for the Nuclear Thermal Rocket Element Environmental Simulator (NTREES)", AIAA- 2006-5270, July 2006.

[17] Schnitzler, Bruce G., and Borowski, Stanley K., "Neutronics Models and Analysis of Small Nuclear Rocket Engine (SNRE)", AIAA-2007-5618, July 2007.

[18] Stewart, Mark E., and Schnitzler, Bruce G., "Thermal Hydraulic Simulations of NTP Reactor Core", AIAA2007-5619, July 2007.

[19] Fittje, James E., "Upgrades to the NESS (Nuclear Engine System Simulation) Code", AIAA-2007-5620, July 2007.

[20] Howe, Steven D., Travis, B., and Zerkle, D.K., "SAFE Testing of Nuclear Rockets", Journal of Propulsion and Power, Vol. 17, No. 3, pg. 534-539 (2001).

[21] Joyner, C. R., Levack, D., and Borowski, S. K., "Affordable Development of a Nuclear Thermal Propulsion Flight Demonstrator Based on a Small Propulsion Engine that is Scalable to Human Missions", GLEX2012.4.4x12224, Global Space Exploration Conference, Washington, DC, May 2012.

[22] Joyner, C. R., Levack, D., and Borowski, S. K., "Development of a Small Nuclear Thermal Propulsion Flight Demonstrator Concept that is Scalable to Human Missions", $48^{\text {th }}$ AIAA/ASME/SAE/ASEE Joint Propulsion Conference, Atlanta, GA, July 29 - August 1, 2012. 